Peykani, P., E. Mohammadi, A. Emrouznejad, M. S. Pishvaee, M. Rostamy-Malkhalifeh (2019). Fuzzy Data

Envelopment Analysis: An Adjustable Approach, Expert Systems with Applications, Accepted (doi)

\title{
Fuzzy Data Envelopment Analysis: An Adjustable Approach
}

\author{
P. Peykania , E. Mohammadi ${ }^{a}$, A. Emrouznejad ${ }^{c, *}$, M. S. Pishvaee ${ }^{a}$, M. Rostamy-Malkhalifeh \\ ${ }^{a}$ School of Industrial Engineering, Iran University of Science and Technology, Tehran, Iran \\ ${ }^{b}$ Aston Business School, Aston University, Birmingham,UK, a.emrouznejad@aston.ac.uk \\ ${ }^{c}$ Faculty of Science, Science and Research Branch, Islamic Azad University, Tehran, Iran, mohsen_rostamy@yahoo.com
}

\begin{abstract}
Possibilistic Data Envelopment Analysis (PDEA) is one of the most applicable and popular approaches in the literature to deal with imprecise and ambiguous data in DEA models. In this approach, with respect to tendency of decision maker (DM) in taking optimistic, pessimistic and compromise attitude, three measures including possibility, necessity and credibility measures are used to form the Fuzzy DEA (FDEA) models, respectively. However, decision makers may have different preference and so it is necessary to customize fuzzy DEA models according to properties of DMUs. This paper proposes a novel fuzzy DEA model based on general fuzzy measure in which the attitude of DMUs could be determined by the optimistic-pessimistic parameters. As a result, the proposed FDEA model is general, applicable, flexible, and adjustable based on each DMUs. A numerical example is used to explain the proposed approach while usefulness and applicability of this approach have been illustrated using a real data set to measure efficiency of 38 hospital in United States.
\end{abstract}

Keywords: Fuzzy Data Envelopment Analysis, General Fuzzy Measure, Possibility Theory, Uncertainty, Hospital Efficiency

\section{Introduction}

Data Envelopment Analysis (DEA) is a popular and applicable approach for measuring the relative efficiency and ranking the homogeneous decision making units (DMUs) that it is widely applied in various and different fields such as health care, transportation, education, power, energy, tourism, banking, insurance and finance (Emrouznejad and Yang, 2018). It should be noted that assume that the input output data are certain and precise. However, crisp inputs and outputs data sometimes are unavailable in many

\footnotetext{
* Corresponding Author: Ali Emrouznejad, Professor of Business Analytics, Aston Business School, Aston University, Birmingham, UK, E-mail: a.emrouznejad@aston.ac.uk, Website: http://www.deazone.com
} 
real-world applications. As a result, it is essential to propose methods and models that can measure performance of DMUs in the presence of vague and imprecise data.

One of the wieldy used approaches for dealing with imprecise and ambiguous data is fuzzy Data Envelopment Analysis (FDEA) (Kahraman and Tolga, 1998). Hatami-Marbini et al. (2011) classified FDEA studies into four groups: (1) the tolerance approach, (2) the fuzzy ranking approach, (3) the $\alpha$-level based approach, and (4) the possibility approach. Emrouznejad et al. (2014) added two more groups to the classification of Hatami-Marbini et al. (2011) including (5) the fuzzy arithmetic approach and (6) the fuzzy random/type-2 fuzzy set approach. According to the aforementioned classification, the possibilistic programming approach is one of the applicable approaches in FDEA field (Peykani et al., 2018). This approach is extended for dealing with the uncertainty issue in input parameters when the access to historical data is limited (Pishvaee et al., 2012). Here we briefly review the most prominent possibilistic FDEA studies in the literature.

Guo et al. (2000) originated the possibility approach in fuzzy Data Envelopment Analysis models using the CCR model presented by Charnes et al. (1978). They have developed the fuzzy CCR model using the possibility (Pos) and necessity ( $\mathrm{Nec}$ ) measures to deal with agent-client evaluation (ACE) system in the presence of symmetrical triangular fuzzy numbers.

Lertworasirikul (2002) and Lertworasirikul et al. (2002a, b) have applied possibility and credibility (Cr) measures to solve a ranking problem by a FDEA model. The possibility approach uses the possibility measure and chance-constrained programming (CCP) methods which is proposed by Charnes and Cooper (1959) to introduce the fuzzy DEA model. In the credibility approach, firstly the FDEA model is converted into a credibility programming and then replaces by fuzzy variables by expected credits which were obtained by applying the credibility measure. The possibility and credibility-based DEA models presented in Lertworasirikul (2002), are formed based on the CCR model and it is assumed that fuzzy inputs and outputs of the FDEA model are normal and convex.

Lertworasirikul et al. (2003a) applied a possibility measure and the concept of CCP to transform the fuzzy CCR model into a possibility LP problem. They compared their proposed approach with the $\alpha$-level fuzzy approach. The fuzzy inputs and outputs of the proposed FDEA model are normal and convex. Moreover, if the fuzzy data are triangular or trapezoidal fuzzy numbers, then the FDEA model turns to an LP model. They also proposed an FDEA model on the basis of the necessity measure. Lertworasirikul et al. (2003b) extended a FDEA model based on the BCC approach presented by Banker et al. (1984) to consider variable returns to scale utilizing the possibility and credibility approaches of Lertworasirikul (2002). This approach also disclosed the relationship between the primal and dual FDEA models. The efficiency obtained through their possibility approach provides the upper and lower bounds for each DMU 
for a given possibility level. Lertworasirikul et al. (2003c) presented a credibility-based approach as an alternative way for solving FDEA models.

Garcia et al. (2005) proposed a fuzzy CCR model by applying the possibility approach of Lertworasirikul et al. (2003a) for determining the ranking indices among failure modes in which the typical failure mode and effects analysis (FMEA) parameters are modeled as fuzzy sets. In their model, the experts can be used linguistic variables in assigning more important values for the considered indices. Wu et al. (2006) employed the formulation of Lertworasirikul et al. (2003a) in the multiplier and envelopment forms of CCR and BCC models to deal with the quantitative and linguistic variables for efficiency analysis of cross-region bank branches in Canada. Wen and You (2007) presented an FDEA model using credibility approach. Jiang and Yang (2007) introduced a fuzzy chance-constrained (FCC) DEA model based on creditability measure and suggested a method for converting the fuzzy programming to a deterministic programming.

Wen and Li (2009) utilized a credibility measure to represent fuzzy CCR model and use a hybrid intelligent algorithm which integrates fuzzy simulations and genetic algorithms (GA) to solve the proposed model. If the inputs and outputs are triangular or trapezoidal fuzzy variables, then their model can be transformed to a LP model. Lin (2010) proposed a three-phase approach as a decision support technique by integrating analytic network process (ANP) and FDEA model based on Lertworasirikul et al. (2003a) to tackle the personnel selection problem in electric and machinery company in Taiwan. Zerafat Angiz et al (2010) presented a non-radial FDEA while Wen et al. (2010) extended the fuzzy CCR model based on the credibility measure and suggested a hybrid algorithm combined with fuzzy simulation and GA to solve the proposed fuzzy DEA model.

Khodabakhshi et al. (2010) introduced two alternative fuzzy and stochastic DEA models based on the additive model presented by Charnes et al. (1985) to estimate returns to scale. The former model considers stochastic inputs and/or outputs variables and the latter model takes fuzzy variables into consideration. Wang and Chin (2011) employed an FDEA model to calculate the best and the worst values of efficiency for selection of a flexible manufacturing system (FMS) by utilizing a fuzzy expected value (EV) approach with either fuzzy or crisp multipliers. In their study, the optimistic and pessimistic values of efficiency are geometrically averaged to rank all DMUs.

Wen et al. (2011) examined the stability and sensitivity analysis of the FDEA model of Wen and You (2007) using credibility measure. Hossainzadeh et al. (2011) presented a fuzzy CCR model with fuzzy chance- constraint multi-objective programming (CCMOP) method using the credibility measure. Firstly, they converted the FDEA model into a MOP model by considering optimistic, pessimistic, and expected values. Then, a goal programming (GP) technique is applied for solving the MOP by transforming the proposed model to a linear programming. 
Zerafat Angiz et al (2012) developed a fuzzy DEA discrete approach and Zhao and Yue (2012) proposed a two-subsystem FDEA model based on the fuzzy DEA model of Lertworasirikul et al. (2003a) to assess the mutual funds management companies in China. By using the possibility approach of Lertworasirikul et al. (2003a), Nedeljkovic'and Drenovac (2012) linearized the fuzzy CCR model in order to calculate the technical efficiency of Serbian delivery post offices. Payan and Sharifi (2013) extended an approach to measure the fuzzy Malmquist productivity index (MPI) by using the credibility theory in order to evaluate the social security organizations.

Agarwal (2014) presented a fuzzy slack based measure (SBM) model based on possibility measure for performance measurement under fuzzy environment. Payan (2015) proposed a credibility-based fuzzy DEA model according to common set of weights Data Envelopment Analysis (CSWDEA) approach and utilized this model to performance assessment of chief executive officers of U.S. public banks and thrifts. Ruiz and Sirvent (2017) developed a fuzzy cross-efficiency evaluation based on the possibility approach of Lertworasirikul et al. (2003a).

Ahmadvand and Pishvaee (2017) introduced a fuzzy CSWDEA based on credibility approach for kidney allocation problem. They applied their model in a real case study from the Iranian kidney allocation system. Peykani et al. (2018) presented several robust fuzzy Data Envelopment Analysis (RFDEA) models based on possibility, necessity and credibility measures using the robust possibilistic programming (RPP) approach of Pishvaee et al. (2012). Further, Peykani and Mohammadi (2019) proposed possibilistic range directional measure model for ranking of stocks in the presence of negative data and uncertainty.

In this paper, a novel fuzzy DEA model is formulated based on general fuzzy (GF) measure in which different attitudes of DM could be considered by optimistic-pessimistic parameter. GF is a flexible and adjustable measure which measures the chances of occurrence of fuzzy events in a decision making problem. Finally, to evaluate the validity, efficacy and applicability of the presented model, a numerical example and a real-life case study related to health care are proposed and examined.

The rest of this paper is organized as follows. Section 2 provides the nomenclatures and background involving the DEA method and fuzzy event via general fuzzy measure. The Adjustable fuzzy DEA model based on general fuzzy measure is proposed in Section 3. Section 4 illustrates the model using a numerical example. This is followed by a real application of measuring efficiency of 38 hospitals in USA to show the applicability and usefulness of eth model. Then, managerial implication is discussed in Section 5. Finally, conclusions and some directions for future research are given in Section 6.

\section{Nomenclatures and background}

2.1. The nomenclatures of Paper 
The indices, parameters and variables that will be used in this study are described as follow:

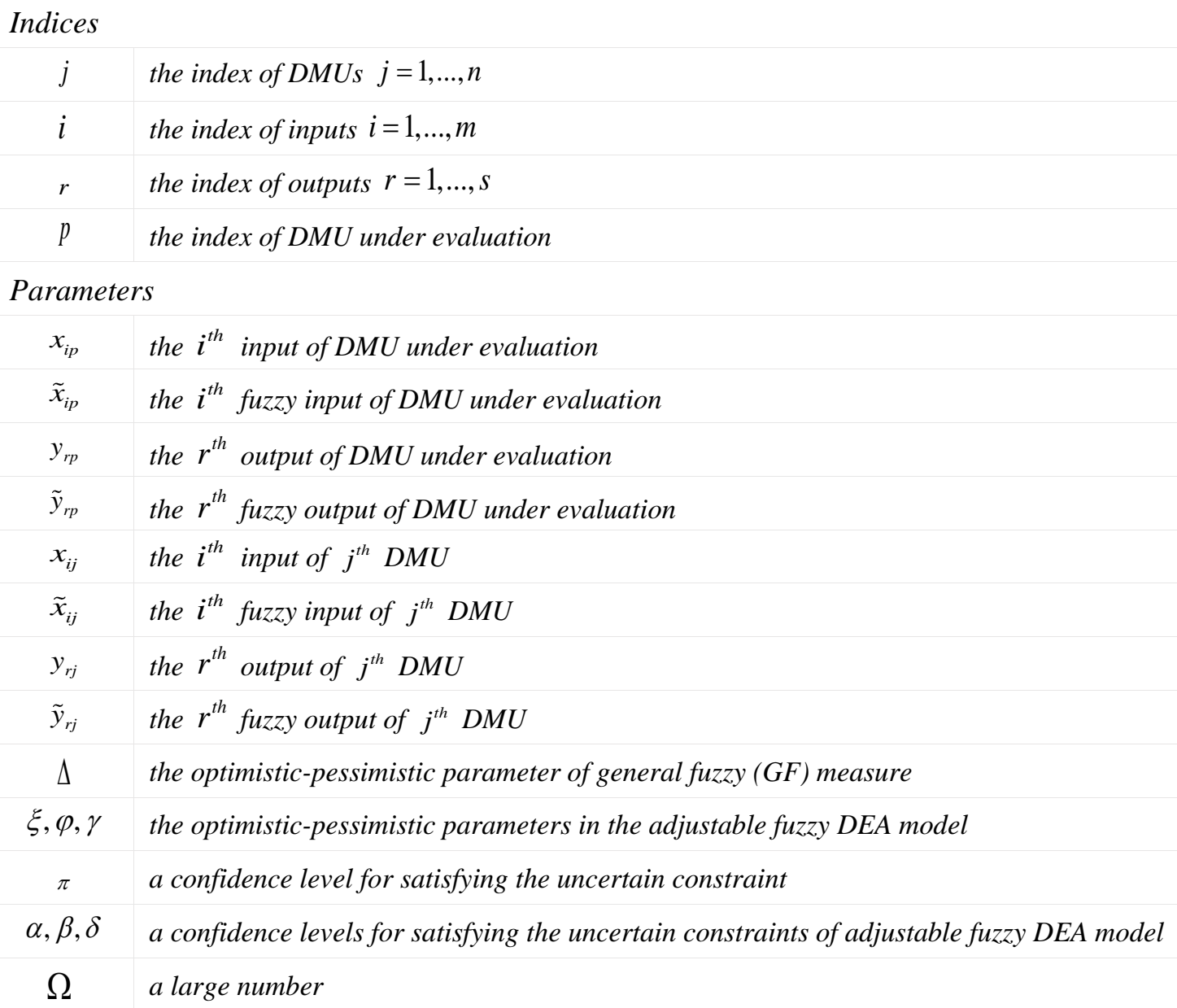

\section{Decision Variables}

$v_{i} \quad$ the weight for the $i^{\text {th }}$ input

$u_{r} \quad$ the weight for the $r^{\text {th }}$ output

$\Theta \quad$ a continues variable for converting of objective function to constraint

$\Psi, \Phi, \Gamma \quad$ a binary variables for linearization of incompatible constraints

\subsection{Data Envelopment Analysis}

DEA is one of the prominent non-parametric performance measurement techniques which takes multiple inputs to produce multiple outputs into consideration in order to measure the efficiency as well as ranking a set of similar DMUs. This methodology was proposed by Charnes et al. (1978) for the first time and it is based on Farrell's (1957) idea. As a matter of fact, Charnes et al. (1978) proposed the following CCR model that is based on the constant returns to scale (CRS) assumption: 
$\operatorname{Max} \sum_{r=1}^{s} y_{r p} u_{r}$

S.t. $\quad \sum_{i=1}^{m} x_{i p} v_{i}=1$

$$
\begin{aligned}
& \sum_{r=1}^{s} y_{r j} u_{r}-\sum_{i=1}^{m} x_{i j} v_{i} \leq 0, \quad \forall j \\
& u_{r}, v_{i} \geq 0, \quad \forall r, i
\end{aligned}
$$

It should be noted that in Model (1), it is assumed that inputs and outputs are positive $(x, y \geq 0)$. Model (1) is the input-oriented multiplier form of the CCR (CCR-IO) model which possesses radial projection constructs. It should be noted that the CCR model was later developed by Banker et al. (1984), to measure efficiency under the assumption of variable returns to scale (VRS).

\subsection{Fuzzy event via General Fuzzy (GF) measure}

Zadeh (1978) was the pioneer researcher in possibilistic programming that proposed the fundamental principles of possibility theory and then many studies have been done to extend the possibility theory. He propounded that the possibility theory is a mathematical theory to model certain types of uncertainty as an alternative for probability theory.

Since, in fuzzy linear programming (FLP) models, fuzzy coefficients can be viewed as fuzzy variables and constraints can be considered as fuzzy events, the possibility of fuzzy events can be defined by applying the possibility theory (Emrouznejad et al. 2014). So, in order to measure the chances of occurrence of fuzzy events, the basic possibility (Pos) and necessity ( $\mathrm{Nec}$ ) measures are introduced with optimistic and pessimistic viewpoints, respectively (Dubois and Prade 1978, 1988). Then, the credibility (Cr) measure is determined as an average of the possibility and necessity measures (Liu and Liu, 2002). Finally the general

fuzzy (GF) measure that is equal to the convex combination of possibility and necessity measures, is proposed (Xu and Zhou, 2011). The definition and properties of the general fuzzy measure will be intruded in following.

Let the triple $(\Upsilon, P(\Upsilon), P o s)$ be a possibility space where $\Upsilon$ is the universe and non-empty set containing all possible events, $P(\Upsilon)$ is the power set of $\Upsilon$ and $A$ is a set in $P(\Upsilon)$. The general fuzzy (GF) measure of $\{\mathrm{A}\}$ is defined on $(\Upsilon, P(\Upsilon), P o s)$ as Equation (2):

$$
G F\{\mathrm{~A}\}=\Delta \operatorname{Pos}\{\mathrm{A}\}+(1-\Delta) \operatorname{Nec}\{\mathrm{A}\}=N e c\{\mathrm{~A}\}+\Delta(\operatorname{Pos}\{\mathrm{A}\}-N e c\{\mathrm{~A}\})
$$


In the GF measure, $\Delta(0 \leq \Delta \leq 1)$ is the optimistic-pessimistic parameter to determine the attitude of a decision maker.

$$
G F\{\mathrm{~A}\}= \begin{cases}\operatorname{Nec}\{\mathrm{A}\}, & \text { if } \Delta=0 ; \\ \operatorname{Cr}\{\mathrm{A}\}, & \text { if } \Delta=0.5 ; \\ \operatorname{Pos}\{\mathrm{A}\}, & \text { if } \Delta=1 .\end{cases}
$$

Let $\zeta$ be a fuzzy variable with trapezoidal distribution that is determined by $\zeta\left(\zeta_{1}, \zeta_{2}, \zeta_{3}, \zeta_{4}\right)$, $\zeta_{1} \leq \zeta_{2} \leq \zeta_{3} \leq \zeta_{4}$ on the possibility space $(\Upsilon, P(\Upsilon), P o s)$ and $\varpi$ be a crisp number. The GF measure of fuzzy events $\{\zeta \leq \tilde{\omega}\},\{\zeta \geq \tilde{\omega}\},\{\zeta \leq \varpi\}$ and $\{\zeta \geq \varpi\}$ are shown in Equations (4) to (7), respectively:

$$
\begin{aligned}
& G F\{\zeta \leq \tilde{\varpi}\}= \begin{cases}0, & \text { if } \zeta_{1} \geq \varpi ; \\
\Delta \frac{\varpi_{4}-\zeta_{1}}{\varpi_{4}-\varpi_{3}+\zeta_{2}-\zeta_{1}}, & \text { if } \zeta_{1} \leq \varpi \leq \zeta_{2} ; \\
\Delta, & \text { if } \zeta_{2} \leq \varpi \leq \zeta_{3} \\
\Delta+(1-\Delta) \frac{\varpi_{2}-\zeta_{3}}{\zeta_{4}-\zeta_{3}+\varpi_{2}-\varpi_{1}}, & \text { if } \zeta_{3} \leq \varpi \leq \zeta_{4} ; \\
1, & \text { if } \zeta_{4} \leq \varpi .\end{cases}
\end{aligned}
$$

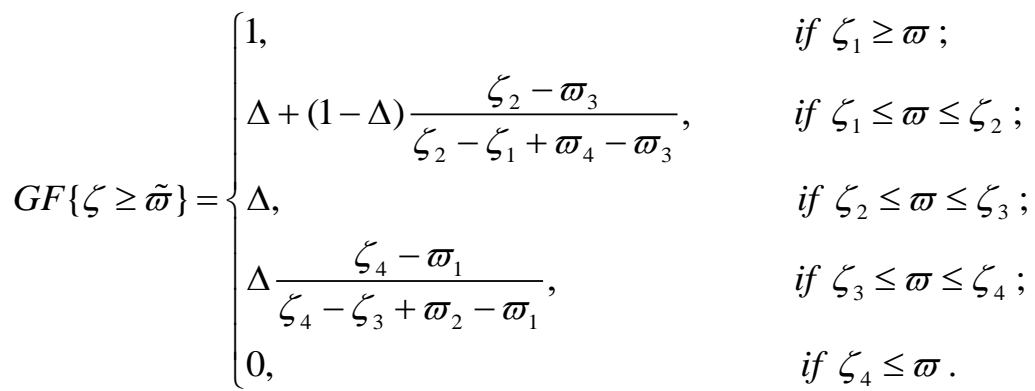

$$
G F\{\zeta \leq \varpi\}= \begin{cases}0, & \text { if } \zeta_{1} \geq \varpi ; \\ \Delta \frac{\varpi-\zeta_{1}}{\zeta_{2}-\zeta_{1}}, & \text { if } \zeta_{1} \leq \varpi \leq \zeta_{2} ; \\ \Delta, & \text { if } \zeta_{2} \leq \varpi \leq \zeta_{3} \\ \Delta+(1-\Delta) \frac{\varpi-\zeta_{3}}{\zeta_{4}-\zeta_{3}}, & \text { if } \zeta_{3} \leq \varpi \leq \zeta_{4} \\ 1, & \text { if } \zeta_{4} \leq \varpi .\end{cases}
$$




$$
G F\{\zeta \geq \varpi\}= \begin{cases}1, & \text { if } \zeta_{1} \geq \varpi ; \\ \Delta+(1-\Delta) \frac{\zeta_{2}-\varpi}{\zeta_{2}-\zeta_{1}}, & \text { if } \zeta_{1} \leq \varpi \leq \zeta_{2} ; \\ \Delta, & \text { if } \zeta_{2} \leq \varpi \leq \zeta_{3} ; \\ \Delta \frac{\zeta_{4}-\varpi}{\zeta_{4}-\zeta_{3}}, & \text { if } \zeta_{3} \leq \varpi \leq \zeta_{4} ; \\ 0, & \text { if } \zeta_{4} \leq \varpi .\end{cases}
$$

According to the GF measure, the fuzzy chance constraints can be converted into their equivalent crisp ones in the desired confidence level $(\pi)$ as follows:

$$
\begin{aligned}
& G F\{\zeta \leq \tilde{\varpi}\} \geq \pi \Leftrightarrow \begin{cases}\operatorname{Nec}\{\zeta \leq \tilde{\varpi}\} \geq \frac{\pi-\Delta}{1-\Delta}, & \text { if } \pi>\Delta ; \\
\operatorname{Pos}\{\zeta \leq \tilde{\varpi}\} \geq \frac{\pi}{\Delta}, & \text { if } \pi \leq \Delta .\end{cases} \\
& G F\{\zeta \geq \tilde{\varpi}\} \geq \pi \Leftrightarrow \begin{cases}\operatorname{Nec}\{\zeta \geq \tilde{\varpi}\} \geq \frac{\pi-\Delta}{1-\Delta}, & \text { if } \pi>\Delta ; \\
\operatorname{Pos}\{\zeta \geq \tilde{\varpi}\} \geq \frac{\pi}{\Delta}, & \text { if } \pi \leq \Delta .\end{cases} \\
& G F\{\zeta \leq \varpi\} \geq \pi \Leftrightarrow \begin{cases}\operatorname{Nec}\{\zeta \leq \varpi\} \geq \frac{\pi-\Delta}{1-\Delta}, & \text { if } \pi>\Delta ; \\
\operatorname{Pos}\{\zeta \leq \varpi\} \geq \frac{\pi}{\Delta}, & \text { if } \pi \leq \Delta .\end{cases} \\
& G F\{\zeta \geq \varpi\} \geq \pi \Leftrightarrow \begin{cases}\operatorname{Nec}\{\zeta \geq \varpi\} \geq \frac{\pi-\Delta}{1-\Delta}, & \text { if } \pi>\Delta ; \\
\operatorname{Pos}\{\zeta \geq \varpi\} \geq \frac{\pi}{\Delta}, & \text { if } \pi \leq \Delta .\end{cases}
\end{aligned}
$$

Or, equivalently

$$
G F\{\zeta \leq \tilde{\varpi}\} \geq \pi \Leftrightarrow \begin{cases}\left(1-\frac{\pi-\Delta}{1-\Delta}\right) \zeta_{3}+\left(\frac{\pi-\Delta}{1-\Delta}\right) \zeta_{4} \leq\left(\frac{\pi-\Delta}{1-\Delta}\right) \varpi_{1}+\left(1-\frac{\pi-\Delta}{1-\Delta}\right) \varpi_{2}, & \text { if } \pi>\Delta ; \\ \left(1-\frac{\pi}{\Delta}\right) \zeta_{1}+\left(\frac{\pi}{\Delta}\right) \zeta_{2} \leq\left(\frac{\pi}{\Delta}\right) \varpi_{3}+\left(1-\frac{\pi}{\Delta}\right) \varpi_{4}, & \text { if } \pi \leq \Delta .\end{cases}
$$




$$
\begin{aligned}
& G F\{\zeta \geq \tilde{\varpi}\} \geq \pi \Leftrightarrow \begin{cases}\left(\frac{\pi-\Delta}{1-\Delta}\right) \zeta_{1}+\left(1-\frac{\pi-\Delta}{1-\Delta}\right) \zeta_{2} \geq\left(1-\frac{\pi-\Delta}{1-\Delta}\right) \varpi_{3}+\left(\frac{\pi-\Delta}{1-\Delta}\right) \varpi_{4}, & \text { if } \pi>\Delta ; \\
\left(\frac{\pi}{\Delta}\right) \zeta_{3}+\left(1-\frac{\pi}{\Delta}\right) \zeta_{4} \geq\left(1-\frac{\pi}{\Delta}\right) \varpi_{1}+\left(\frac{\pi}{\Delta}\right) \varpi_{2}, & \text { if } \pi \leq \Delta\end{cases} \\
& G F\{\zeta \leq \varpi\} \geq \pi \Leftrightarrow \begin{cases}\left(1-\frac{\pi-\Delta}{1-\Delta}\right) \zeta_{3}+\left(\frac{\pi-\Delta}{1-\Delta}\right) \zeta_{4} \leq \varpi, & \text { if } \pi>\Delta ; \\
\left(1-\frac{\pi}{\Delta}\right) \zeta_{1}+\left(\frac{\pi}{\Delta}\right) \zeta_{2} \leq \varpi, & \text { if } \pi \leq \Delta .\end{cases} \\
& G F\{\zeta \geq \varpi\} \geq \pi \Leftrightarrow \begin{cases}\left(\frac{\pi-\Delta}{1-\Delta}\right) \zeta_{1}+\left(1-\frac{\pi-\Delta}{1-\Delta}\right) \zeta_{2} \geq \varpi, & \text { if } \pi>\Delta ; \\
\left(\frac{\pi}{\Delta}\right) \zeta_{3}+\left(1-\frac{\pi}{\Delta}\right) \zeta_{4} \geq \varpi, & \text { if } \pi \leq \Delta .\end{cases}
\end{aligned}
$$

In the GF measure, $\Delta=0, \Delta=1$ and $\Delta=0.5$ indicate that the DM takes pessimistic, optimistic, and compromise attitudes, respectively. It should be noted that the relations and formulations of fuzzy event via possibility, necessity and credibility measures are explained in Appendix A.

\section{An Adjustable Fuzzy Data Envelopment Analysis (AFDEA) model}

In this section, we propose a novel FDEA model, based on general fuzzy measure, that is capable to consider different attitude of each decision maker. It should be noted that the developed Fuzzy Data Envelopment Analysis model in this study is based on constant returns to scale model and uncertainties are intended to be in inputs and outputs. To consider the uncertainty on inputs and outputs, we begin with the following model which is equivalent to Model (1) (for more details see Peykani et al. (2018)):

$$
\begin{array}{ll}
\operatorname{Max} & \sum_{r=1}^{s} y_{r p} u_{r} \\
\text { S.t. } & \sum_{i=1}^{m} x_{i p} v_{i} \leq 1 \\
& \sum_{r=1}^{s} y_{r j} u_{r}-\sum_{i=1}^{m} x_{i j} v_{i} \leq 0, \quad \forall j \\
& u_{r}, v_{i} \geq 0, \quad \forall r, i
\end{array}
$$


Now, by converting the objective function into constraint and assuming that the fuzzy inputs and fuzzy outputs have a trapezoidal distribution $\tilde{x}\left(x^{1}, x^{2}, x^{3}, x^{4}\right)$ and $\tilde{y}\left(y^{1}, y^{2}, y^{3}, y^{4}\right)$ in which $x^{1} \leq x^{2} \leq x^{3} \leq x^{4}$ and $y^{1} \leq y^{2} \leq y^{3} \leq y^{4}$, the fuzzy DEA model can be considered as Model (17):

$\operatorname{Max} \Theta$

S.t. $\quad \sum_{r=1}^{s} \tilde{y}_{r p} u_{r} \geq \Theta$

$$
\begin{aligned}
& \sum_{i=1}^{m} \tilde{x}_{i p} v_{i} \leq 1 \\
& \sum_{r=1}^{s} \tilde{y}_{r j} u_{r}-\sum_{i=1}^{m} \tilde{x}_{i j} v_{i} \leq 0, \quad \forall j \\
& u_{r}, v_{i} \geq 0, \quad \forall r, i
\end{aligned}
$$

Therefore, in order to deal with uncertainty of chance constraints in fuzzy DEA model and convert them to their equivalent crisp values, GF measure can be used. According to GF measure, the fuzzy Data Envelopment Analysis (FDEA) model is defined as Model (18):

$\operatorname{Max} \Theta$

$$
\begin{array}{ll}
\text { S.t. } & G F\left\{\sum_{r=1}^{s} \tilde{y}_{r p} u_{r} \geq \Theta\right\} \geq \alpha \\
& G F\left\{\sum_{i=1}^{m} x_{i p} v_{i} \leq 1\right\} \geq \beta \\
& G F\left\{\sum_{r=1}^{s} \tilde{y}_{r j} u_{r}-\sum_{i=1}^{m} x_{i j} v_{i} \leq 0\right\} \geq \delta_{j}, \quad \forall j \\
& u_{r}, v_{i} \geq 0, \quad \forall r, i
\end{array}
$$

It should be noted that $\alpha, \beta$ and $\delta_{j}$ are confidence levels for satisfying the fuzzy chance constraints in FDEA model. Then, by using Equations (12) to (15), an equivalent crisp forms of fuzzy chance constraints according under specific confidence level can be written as Model (19) where $\xi, \varphi$ and $\gamma_{j}$ are the optimistic-pessimistic parameters of general fuzzy measure. 
S.t. $\begin{cases}\sum_{r=1}^{s}\left(\left(\frac{\alpha-\xi}{1-\xi}\right) y_{r p}^{1}+\left(1-\frac{\alpha-\xi}{1-\xi}\right) y_{r p}^{2}\right) u_{r} \geq \Theta & \text { if } \alpha>\xi ; \\ \sum_{r=1}^{s}\left(\left(\frac{\alpha}{\xi}\right) y_{r p}^{3}+\left(1-\frac{\alpha}{\xi}\right) y_{r p}^{4}\right) u_{r} \geq \Theta & \text { if } \alpha \leq \xi .\end{cases}$

$$
\begin{cases}\sum_{i=1}^{m}\left(\left(1-\frac{\beta-\varphi}{1-\varphi}\right) x_{i p}^{3}+\left(\frac{\beta-\varphi}{1-\varphi}\right) x_{i p}^{4}\right) v_{i} \leq 1 & \text { if } \beta>\varphi ; \\ \sum_{i=1}^{m}\left(\left(1-\frac{\beta}{\varphi}\right) x_{i p}^{1}+\left(\frac{\beta}{\varphi}\right) x_{i p}^{2}\right) v_{i} \leq 1 & \text { if } \beta \leq \varphi .\end{cases}
$$

$$
\begin{aligned}
& \left\{\begin{array}{l}
\sum_{r=1}^{s}\left(\left(1-\frac{\delta_{j}-\gamma_{j}}{1-\gamma_{j}}\right) y_{r j}^{3}+\left(\frac{\delta_{j}-\gamma_{j}}{1-\gamma_{j}}\right) y_{r j}^{4}\right) u_{r} \\
-\sum_{i=1}^{m}\left(\left(\frac{\delta_{j}-\gamma_{j}}{1-\gamma_{j}}\right) x_{i j}^{1}+\left(1-\frac{\delta_{j}-\gamma_{j}}{1-\gamma_{j}}\right) x_{i j}^{2}\right) v_{i} \leq 0, \quad \forall j \quad \text { if } \delta_{j}>\gamma_{j} \\
\sum_{r=1}^{s}\left(\left(1-\frac{\delta_{j}}{\gamma_{j}}\right) y_{r j}^{1}+\left(\frac{\delta_{j}}{\gamma_{j}}\right) y_{r j}^{2}\right) u_{r} \\
-\sum_{i=1}^{m}\left(\left(\frac{\delta_{j}}{\gamma_{j}}\right) x_{i j}^{3}+\left(1-\frac{\delta_{j}}{\gamma_{j}}\right) x_{i j}^{4}\right) v_{i} \leq 0,
\end{array}\right. \\
& u_{r}, v_{i} \geq 0, \quad \forall r, i
\end{aligned}
$$

As it can be seen from Model (19), for the confidence levels greater or less than GF parameters, an equivalent crisp of fuzzy chance constraints is different. So, by applying a binary variables $(\Psi, \Phi, \Gamma$ ) and a sufficient big number ( $\Omega$ ), the linearization of incompatible constraints for the confidence levels of greater or less than GF parameters are made. Finally, the novel fuzzy Data Envelopment Analysis model based on GF approach is proposed as Model (20): 


$$
\begin{aligned}
& \text { S.t. } \sum_{r=1}^{s}\left(\left(\frac{\alpha-\xi}{1-\xi}\right) y_{r p}^{1}+\left(\frac{1-\alpha}{1-\xi}\right) y_{r p}^{2}\right) u_{r} \geq \Theta-\Omega \Psi \\
& \sum_{r=1}^{s}\left(\left(\frac{\alpha}{\lambda}\right) y_{r p}^{3}+\left(\frac{\lambda-\alpha}{\lambda}\right) y_{r p}^{4}\right) u_{r} \geq \Theta-\Omega(1-\Psi) \\
& \sum_{i=1}^{m}\left(\left(\frac{1-\beta}{1-\varphi}\right) x_{i p}^{3}+\left(\frac{\beta-\varphi}{1-\varphi}\right) x_{i p}^{4}\right) v_{i} \leq 1+\Omega \Phi \\
& \sum_{i=1}^{m}\left(\left(\frac{\varphi-\beta}{\varphi}\right) x_{i p}^{1}+\left(\frac{\beta}{\varphi}\right) x_{i p}^{2}\right) v_{i} \leq 1+\Omega(1-\Phi) \\
& \sum_{r=1}^{s}\left(\left(\frac{1-\delta_{j}}{1-\gamma_{j}}\right) y_{r j}^{3}+\left(\frac{\delta_{j}-\gamma_{j}}{1-\gamma_{j}}\right) y_{r j}^{4}\right) u_{r}-\sum_{i=1}^{m}\left(\left(\frac{\delta_{j}-\gamma_{j}}{1-\gamma_{j}}\right) x_{i j}^{1}+\left(\frac{1-\delta_{j}}{1-\gamma_{j}}\right) x_{i j}^{2}\right) v_{i} \leq \Omega \Gamma_{j}, \quad \forall j \\
& \sum_{r=1}^{s}\left(\left(\frac{\gamma_{j}-\delta_{j}}{\gamma_{j}}\right) y_{r j}^{1}+\left(\frac{\delta_{j}}{\gamma_{j}}\right) y_{r j}^{2}\right) u_{r}-\sum_{i=1}^{m}\left(\left(\frac{\delta_{j}}{\gamma_{j}}\right) x_{i j}^{3}+\left(\frac{\gamma_{j}-\delta_{j}}{\gamma_{j}}\right) x_{i j}^{4}\right) v_{i} \leq \Omega\left(1-\Gamma_{j}\right), \quad \forall j \\
& \alpha>\xi-\Omega \Psi \\
& \alpha \leq \xi+\Omega(1-\Psi) \\
& \beta>\varphi-\Omega \Phi \\
& \beta \leq \varphi+\Omega(1-\Phi) \\
& \delta_{j}>\gamma_{j}-\Omega \Gamma_{j}, \quad \forall j \\
& \delta_{j} \leq \gamma_{j}+\Omega\left(1-\Gamma_{j}\right), \quad \forall j \\
& \Psi, \Phi, \Gamma_{j} \in\{0,1\}, \quad \forall j \\
& u_{r}, v_{i} \geq 0, \quad \forall r, i
\end{aligned}
$$


Model (20) is the adjustable fuzzy DEA (AFDEA) model that DM can determine different attitudes by setting the optimistic-pessimistic parameters $\xi, \varphi$ and $\gamma_{j}$. If the decision maker takes the optimisticpessimistic viewpoint and all of the uncertain constraints are converted to their equivalent crisp ones by the same confidence levels, then the following definitions can be used to classify the DMUs:

Definition 1. A DMU is ultra-efficient $\left(E^{++}\right)$if its $\Theta$ values for all various optimistic-pessimistic viewpoints and confidence levels are greater than or equal to one.

Definition 2. A DMU is marginal-efficient $\left(E^{+}\right)$if its $\Theta$ values for some of optimistic-pessimistic viewpoints and confidence levels are greater than or equal to one.

Definition 3. A DMU is inefficient $\left(E^{-}\right)$if its $\Theta$ values for all various optimistic-pessimistic viewpoints and confidence levels are less than one.

At the end of this section, it should be noted that in special cases, if the optimistic-pessimistic parameters of AFDEA model are set equal to 1, 0 and 0.5, Model (20) can be converted to FDEA models based on possibility, necessity and credibility measures, respectively. To explain more details about the proposed models, the FDEA models according to possibility, necessity and credibility measures are presented in Appendix B. It should be noted that the in Model (20), fuzzy inputs and fuzzy outputs are trapezoidal fuzzy numbers. The adjustable FDEA model, when fuzzy parameters are triangular fuzzy numbers is introduced in Appendix C.

\section{Numerical results and discussions}

In this section, the implementation of the proposed adjustable fuzzy DEA model will be presented by applying a numerical example and real-life case application.

\subsection{A numerical example}

To illustrate the proposed adjustable fuzzy DEA model, consider the data of 5 DMUs with 2 inputs and 2 outputs presented in Table (1) (also used by Peykani et al., 2018). In this dataset the inputs and outputs have symmetrical trapezoidal membership functions.

Results of the presented AFDEA model based on general fuzzy measure at five different confidence levels and five different optimistic-pessimistic viewpoints are shown in Table (2): 
As it can be seen from Table (2), for the same adjustable parameter (AP), efficiency scores of DMUs decrease while the confidence level (CL) increase. Additionally, for the same CL, when AP increase, the efficiency of DMUs increase (for $\mathrm{AP}=0 \%$ and $\mathrm{AP}=100 \%$ is non-decreasing) and the attitudes of DM are changed from pessimistic to optimistic viewpoint in order to measure the chances of occurrence of fuzzy events.

Furthermore, based on GF measure, when AP is set to 0\%, 50\% and 100\%, the Adjusted FDEA model converts to the standard FDEA model based on necessity $(\mathrm{Nec})$, credibility $(\mathrm{Cr})$ and possibility (Pos) measures, respectively. Generally, minimum value efficiency per DMUs occurred for pair of $(\mathrm{AP}, \mathrm{CL})=$ $(0 \%, 100 \%)$, and maximum value efficiency per DMUs occurred for pair of $(A P, C L)=(100 \%, 0 \%)$. Figure (1) depicts the relations between results of adjustable fuzzy DEA model under different values for adjustable parameter and confidence level.

\section{[Figure 1 ABOUT HERE]}

It should be noted that the analysis of AFDEA model results for this numerical example, indicated that the segments with the same color in Figure (1) have the same efficiency values. For example the segments with red color including 4 pairs of $(0 \%, 100 \%),(25 \%, 100 \%),(50 \%, 100 \%)$, and $(75 \%, 100 \%)$, have the same result. As seen in this figure, in order to achieve the results of 25 segments, it is not necessary to solve all 25 pairs of (AP, CL), and only by solving 14 states of (AP, CL), the results of all segments can be measured.

As previously explained, the traditional DEA models cannot be applied in the presence of ambiguous data. Accordingly, for comparing the proposed method with the traditional DEA, firstly, all fuzzy data should be converted to the crisp numbers. As a result, for defuzzification of all trapezoidal fuzzy numbers that presented in Table (1), the expected value approach is applied as follows (Heilpern, 1992).

$$
\zeta=\frac{\zeta_{1}+\zeta_{2}+\zeta_{3}+\zeta_{4}}{4}
$$

After defuzzification, the classic CCR model has been used. The crisp data as well as efficiency scores and ranking of five DMUs are given in Table (3): 
As it can be seen from Tables (2) and (3), it is obvious that if the traditional CCR model is used instead of adjustable fuzzy CCR (AFCCR) model and the uncertainty in the data is not taken into account, the results and ranking of DMUs may be invalid. Moreover, the discriminatory power of AFCCR model is more than classic CCR model. Also, AFCCR model is capable to be ranked of five DMUs, while traditional CCR model does not have the ability to rank efficient DMUs.

\subsection{A real life application: hospital efficiency}

Data Envelopment Analysis is an effective and popular method for performance measurement and ranking the hospitals (O'Neill et al., 2008). In this section, the proposed method is applied to evaluate 38 hospitals, selected by the Office of Inspector General (OIG) - East Virginia Department of Health and Human Services in the United States to participate in this study. The input and output variables for hospital efficiency measurement are presented in Table (4).

\section{[Table 4 ABOUT HERE]}

As it can be seen from Table (4), the number of beds, labor-related expenses, patient care supplies and other expenses were selected as the input variables. Nonmedical doctors' salaries and wages, fringe benefits, medical doctors' compensation, and non-payroll labor are the labor-related expenses. Food and food service supplies, drugs, medical supplies, and other supplies and expenses are gathered under the patient care supplies and other expenses.

The Output variables include: the number of outpatient department visits, the number of inpatient department admissions, and the overall patient satisfaction. "Outpatient" refers to the procedure that does not require hospital admission and may also be performed outside the premises of a hospital. "Inpatient" refers to the procedure that requires the admission, so that the patient can be closely monitored during the procedure and recovery. The patient satisfaction survey is a short, easily administered questionnaire that provides a hospital with information and insight of their patients' view about the provided services.

Information for these hospitals are taken from Hatami-Marbini et al. (2012). Real world data for the 38 hospitals for the fiscal year 2009 are reproduced in the following Table:

[Table 5 ABOUT HERE]

As shown in Table (5), all data with the exception of patient satisfaction information are crisp values. Patient satisfaction was measured with linguistic variables and the trapezoidal fuzzy numbers (TFN) are presented in Table (6): 
Using linguistic variables allows the patients to easily express their opinion. Then, according to Table (6), instead of linguistic variables, their equivalent fuzzy numbers are applied.

The efficiencies of all hospitals are calculated using the proposed AFDEA model. It should be noted that for performance assessment of hospitals, different values for optimistic-pessimistic parameter and confidence level are considered. Tables (7) to (11) present the efficiency scores for 5 different optimisticpessimistic viewpoints including $0 \%, 25 \%, 50 \%, 75 \%$ and $100 \%$, respectively:

[Tables 7 to 11 ABOUT HERE]

As it can be seen in Tables (7) to (11), all relationships, rules and analyzes that extracted from numerical example that are presented in Figure (1), can be found in a real-life case study. The results show that Hospitals 7 and 19 are ultra-efficient, Hospital 12, 23 and 28 are marginal-efficient and the rest of the hospitals are inefficient.

Also, for ranking all hospitals, the average of all efficiency scores for each hospital under 5 confidence levels for 5 different optimistic-pessimistic viewpoints are measured. The ranking of all hospitals based on AFDEA model is given in Figure (2).

[Figure 2 ABOUT HERE]

According to Figure (2), Hospitals 7 and 19 have the best performance during the year 2009, respectively. Therefore, these two hospitals, can be considered as a benchmark for other hospital managements.

Finally, the results of proposed AFDEA model in this study are compared to the results of FDEA model based on $\alpha$-level based approach that presented in Hatami-Marbini et al. (2012). Table (12) introduce the efficiency scores of hospitals for $5 \alpha$-levels including $0 \%, 25 \%, 50 \%, 75 \%$ and $100 \%$. Also, the average of all efficiency scores for each hospital under $5 \alpha$-levels is presented in Figure (3).

- [Table 12 ABOUT HERE]

[Figure 3 ABOUT HERE]

It can be clearly observed that the discriminatory power of AFDEA model is more than FDEA model. Also, AFDEA model is capable to be used for ranking of all DMUs, while FDEA model does not have the ability to rank efficient DMUs. Additionally, the AFDEA model is general, applicable, flexible and adjustable for different decision makers. 


\section{Managerial implication}

Performance assessment of organizations has always been one of the major concerns of managers. The reason for this is the identification of DMUs with a desirable performance as a benchmark for inefficient DMUs. Undoubtedly, DEA is one of the most powerful and effective approaches that can be used to performance assessment, ranking and benchmarking in a variety of applications and problems.

It should be noted that in many real-world problems, data are tainted by uncertainty. Also, linguistic variables, such as patient satisfaction, are qualitative and should be quantified. Accordingly, the novel version of DEA approach should be proposed that capable to eliminate mentioned issues. The combination of fuzzy mathematical programming and DEA method as an expert system, can be applied to deal with uncertainty and handle of linguistic variables. As a result, there are some practical FDEA models and studies in many real-life applications. For examples, Liu and Chuang (2009), Wang et al. (2009), Amirkhan et al. (2018), Omrani et al. (2018), and Ji et al. (2019), are applied FDEA approach for performance measurement of university libraries, manufacturing companies, supply chain of small and medium-sized enterprises, hospitals and healthcare management, respectively.

In the current study, the adjustable fuzzy DEA approach has been developed that is capable to be used for all attitude of DMs and mangers. According to the implementation of proposed AFDEA model in reallife case study explained in the previous section, the following significant results can be extracted for managers.

The proposed AFDEA approach can be applied in order to presenting an expert system for performance assessment of hospitals. In other words, the AFDEA model can be employed as an engine of healthcare expert system that capable to be used for ranking of hospitals. In addition to the application of AFDEA approach in hospitals, this approach can be applied in any other application that data are ambiguous and vague. Additionally, managers will be able to get information of the range of efficiency scores for each DMU in AFDEA method. As a result, this point can lead managers to better decision-making. Moreover, the proposed adjustable fuzzy DEA approach can be used by managers for performance evaluation of the DMUs that their inputs or outputs data are in the form of linguistic variables.

\section{Conclusions and directions for future research}

In this study, a novel fuzzy Data Envelopment Analysis model based on adjustable approach is proposed. By applying a general fuzzy measure, the proposed adjustable FDEA model is able to cover all previous FDEA models that presented based on possibility, necessity and credibility measures in FDEA literature. In other words, in AFDEA model, unlike the previous FDEA models, there is no need for separate modeling based on different fuzzy measures, and only by setting an adjustable parameter, the desired FDEA model 
can be achieved. Accordingly, mangers can easily consider their different viewpoints in performance appraisal of DMUs without no re-modeling of FDEA. Also, decision makers are able to get information of all efficiency scores based on different optimistic-pessimistic attitudes and confidence levels, therefore, they will be able to make the appropriate decisions. Another advantage of the AFDEA model is that it can be presented in the form of fuzzy linear programing. Additionally, in AFDEA model, the discriminatory power is increased. Therefore, the proposed model, in addition to assessing the performance of DMUs, also has the ability to rank them.

Note that to validate the presented adjustable fuzzy DEA model, this model is implemented for a numerical example and a real case study of health care in order to measure the efficiency of hospitals. For the future studies, adjustable FDEA model could be adopted to many other models to include negative data, for example by extending semi-oriented radial measure (SORM), range directional measure (RDM) and variant of radial measure (VRM) models that presented by Emrouznejad et al (2010), Portela et al. (2004) and Cheng et al. (2013), respectively. Also, the new fuzzy concepts including Z-number, fuzzy type-2, and random fuzzy variables can be applied to propose the new version of AFDEA model (for more details see Azadeh and Kokabi (2016), Qin et al. (2009), and Tavana et al. (2013)). Additionally, the proposed model in this paper can be used to evaluate and rank of DMUs in different applications and real-life case studies in the presence of imprecise and vague data. 


\section{Appendix A. Fuzzy event via Possibility, Necessity and Credibility measures}

\section{A.1. Possibility measure}

The possibility of fuzzy events $\{\zeta \leq \tilde{\omega}\},\{\zeta \geq \tilde{\omega}\},\{\zeta \leq \varpi\}$ and $\{\zeta \geq \varpi\}$ are defined in Equations (A.1) to (A.4), respectively:

$$
\begin{aligned}
& \operatorname{Pos}\{\zeta \leq \tilde{\varpi}\}=\left\{\begin{array}{lr}
0, & \text { if } \zeta_{1} \geq \varpi ; \\
\frac{\varpi_{4}-\zeta_{1}}{\varpi_{4}-\varpi_{3}+\zeta_{2}-\zeta_{1},} & \text { if } \zeta_{1} \leq \varpi \leq \zeta_{2} \\
1, & \text { if } \zeta_{2} \leq \varpi ;
\end{array}\right. \\
& \operatorname{Pos}\{\zeta \geq \tilde{\varpi}\}=\left\{\begin{array}{lr}
1, & \text { if } \varpi \leq \zeta_{3} ; \\
\frac{\zeta_{4}-\varpi_{1}}{\zeta_{4}-\zeta_{3}+\varpi_{2}-\varpi_{1}}, & \text { if } \zeta_{3} \leq \varpi \leq \zeta_{4} \\
0, & \text { if } \zeta_{4} \leq \varpi .
\end{array}\right. \\
& \operatorname{Pos}\{\zeta \leq \varpi\}= \begin{cases}0, & \text { if } \zeta_{1} \leq \varpi \leq \zeta_{2} ; \\
\frac{\varpi-\zeta_{1}}{\zeta_{2}-\zeta_{1}}, & \text { if } \zeta_{2} \leq \varpi ; \\
1, & \text { if } \varpi \leq \zeta_{3} ;\end{cases} \\
& \operatorname{Pos}\{\zeta \geq \varpi\}= \begin{cases}1, & \text { if } \zeta_{3} \leq \varpi \leq \zeta_{4} ; \\
\frac{\zeta_{4}-\varpi}{\zeta_{4}-\zeta_{3}}, & \text { if } \zeta_{4} \leq \varpi . \\
0, & \end{cases}
\end{aligned}
$$

According to in Equations (A.1) to (A.4), the fuzzy chance constraints can be converted into their equivalent crisp ones in the desired confidence level $(\pi)$ as follows:

$$
\begin{aligned}
& \operatorname{Pos}\{\zeta \leq \tilde{\varpi}\} \geq \pi \Leftrightarrow(1-\pi) \zeta_{1}+(\pi) \zeta_{2} \leq(\pi) \varpi_{3}+(1-\pi) \varpi_{4} \\
& \operatorname{Pos}\{\zeta \geq \tilde{\varpi}\} \geq \pi \Leftrightarrow(\pi) \zeta_{3}+(1-\pi) \zeta_{4} \geq(1-\pi) \varpi_{1}+(\pi) \varpi_{2} \\
& \operatorname{Pos}\{\zeta \leq \varpi\} \geq \pi \Leftrightarrow(1-\pi) \zeta_{1}+(\pi) \zeta_{2} \leq \varpi \\
& \operatorname{Pos}\{\zeta \geq \varpi\} \geq \pi \Leftrightarrow(\pi) \zeta_{3}+(1-\pi) \zeta_{4} \geq \varpi
\end{aligned}
$$




\section{A.1.2 Necessity Measure}

The Necessity of fuzzy events $\{\zeta \leq \tilde{w}\},\{\zeta \geq \tilde{w}\},\{\zeta \leq \varpi\}$ and $\{\zeta \geq \varpi\}$ are defined in Equations (A.9) to (A.12), respectively:

$$
\begin{aligned}
& \operatorname{Nec}\{\zeta \leq \tilde{\varpi}\}= \begin{cases}0, & \text { if } \varpi \leq \zeta_{3} ; \\
\frac{\varpi_{2}-\zeta_{3}}{\zeta_{4}-\zeta_{3}+\varpi_{2}-\varpi_{1}}, & \text { if } \zeta_{3} \leq \varpi \leq \zeta_{4} ; \\
1, & \text { if } \zeta_{4} \leq \varpi .\end{cases} \\
& N e c\{\zeta \geq \varpi\}= \begin{cases}1, & \text { if } \zeta_{1} \geq \varpi ; \\
\frac{\zeta_{2}-\varpi_{3}}{\zeta_{2}-\zeta_{1}+\varpi_{4}-\varpi_{3}}, & \text { if } \zeta_{1} \leq \varpi \leq \zeta_{2} \\
0, & \text { if } \zeta_{2} \leq \varpi ;\end{cases} \\
& N e c\{\zeta \leq \varpi\}= \begin{cases}0, & \text { if } \varpi \leq \zeta_{3} ; \\
\frac{\varpi-\zeta_{3}}{\zeta_{4}-\zeta_{3},} & \text { if } \zeta_{3} \leq \varpi \leq \zeta_{4} ; \\
1, & \text { if } \zeta_{4} \leq \varpi .\end{cases} \\
& N e c\{\zeta \geq \varpi\}= \begin{cases}1, & \text { if } \zeta_{1} \geq \varpi ; \\
\frac{\zeta_{2}-\varpi}{\zeta_{2}-\zeta_{1}}, & \text { if } \zeta_{1} \leq \varpi \leq \zeta_{2} \\
0, & \text { if } \zeta_{2} \leq \varpi ;\end{cases}
\end{aligned}
$$

According to Equations (A.9) to (A.12), the fuzzy chance constraints can be converted into their equivalent crisp ones in the desired confidence level $(\pi)$ as follows:

$$
\begin{aligned}
& \operatorname{Nec}\{\zeta \leq \tilde{\varpi}\} \geq \pi \Leftrightarrow(1-\pi) \zeta_{3}+(\pi) \zeta_{4} \leq(\pi) \varpi_{1}+(1-\pi) \varpi_{2} \\
& \operatorname{Nec}\{\zeta \geq \tilde{\varpi}\} \geq \pi \Leftrightarrow(\pi) \zeta_{1}+(1-\pi) \zeta_{2} \geq(1-\pi) \varpi_{3}+(\pi) \varpi_{4} \\
& \operatorname{Nec}\{\zeta \leq \varpi\} \geq \pi \Leftrightarrow(1-\pi) \zeta_{3}+(\pi) \zeta_{4} \leq \varpi \\
& \operatorname{Nec}\{\zeta \geq \varpi\} \geq \pi \Leftrightarrow(\pi) \zeta_{1}+(1-\pi) \zeta_{2} \geq \varpi
\end{aligned}
$$




\section{A.1.3 Credibility Measure}

The Credibility of fuzzy events $\{\zeta \leq \tilde{w}\},\{\zeta \geq \tilde{w}\},\{\zeta \leq \varpi\}$ and $\{\zeta \geq \varpi\}$ are defined in Equations (A.17) to (A.20), respectively:

$$
\begin{aligned}
\operatorname{Cr}\{\zeta \leq \tilde{\omega}\}= \begin{cases}0, & \text { if } \zeta_{1} \geq \varpi ; \\
\frac{\varpi_{4}-\zeta_{1}}{2\left(\varpi_{4}-\varpi_{3}+\zeta_{2}-\zeta_{1}\right)}, & \text { if } \zeta_{1} \leq \varpi \leq \zeta_{2} ; \\
0.5, & \text { if } \zeta_{2} \leq \varpi \leq \zeta_{3} ; \\
\frac{2 \varpi_{2}-\varpi_{1}+\zeta_{4}-2 \zeta_{3}}{2\left(\zeta_{4}-\zeta_{3}+\varpi_{2}-\varpi_{1}\right)}, & \text { if } \zeta_{3} \leq \varpi \leq \zeta_{4} ; \\
1, & \text { if } \zeta_{4} \leq \varpi .\end{cases} \\
\operatorname{Cr}\{\zeta \geq \tilde{\tilde{w}}\}= \begin{cases}\frac{1,}{2 \zeta_{2}-\zeta_{1}+\varpi_{4}-2 \varpi_{3}}, & \text { if } \zeta_{1} \geq \varpi ; \\
\frac{\zeta_{2}-\zeta_{1}+\varpi_{4}-\varpi_{3}}{0.5,} \zeta_{1} \leq \varpi \leq \zeta_{2} ; & \text { if } \zeta_{2} \leq \varpi \leq \zeta_{3} ; \\
\frac{\zeta_{4}-\varpi_{1}}{2\left(\zeta_{4}-\zeta_{3}+\varpi_{2}-\varpi_{1}\right)}, & \text { if } \zeta_{3} \leq \varpi \leq \zeta_{4} ; \\
0, & \text { if } \zeta_{4} \leq \varpi .\end{cases}
\end{aligned}
$$

$$
\operatorname{Cr}\{\zeta \leq \varpi\}= \begin{cases}0, & \text { if } \zeta_{1} \geq \varpi ; \\ \frac{\varpi-\zeta_{1}}{2\left(\zeta_{2}-\zeta_{1}\right)}, & \text { if } \zeta_{1} \leq \varpi \leq \zeta_{2} \\ 0.5, & \text { if } \zeta_{2} \leq \varpi \leq \zeta_{3} \\ \frac{\varpi+\zeta_{4}-2 \zeta_{3}}{2\left(\zeta_{4}-\zeta_{3}\right)}, & \text { if } \zeta_{3} \leq \varpi \leq \zeta_{4} \\ 1, & \text { if } \zeta_{4} \leq \varpi .\end{cases}
$$

$$
\operatorname{Cr}\{\zeta \geq \varpi\}= \begin{cases}1, & \text { if } \zeta_{1} \geq \varpi ; \\ \frac{2 \zeta_{2}-\zeta_{1}-\varpi}{2\left(\zeta_{2}-\zeta_{1}\right)}, & \text { if } \zeta_{1} \leq \varpi \leq \zeta_{2} \\ 0.5, & \text { if } \zeta_{2} \leq \varpi \leq \zeta_{3} \\ \frac{\zeta_{4}-\varpi}{2\left(\zeta_{4}-\zeta_{3}\right)}, & \text { if } \zeta_{3} \leq \varpi \leq \zeta_{4} \\ 0, & \text { if } \zeta_{4} \leq \varpi\end{cases}
$$

According to Equations (A.17) to (A.20), the fuzzy chance constraints can be converted into their equivalent crisp ones in the desired confidence level $(\pi)$ as follows: 


$$
\begin{aligned}
& \operatorname{Cr}\{\zeta \leq \tilde{\varpi}\} \geq \pi \Leftrightarrow \begin{cases}(2-2 \pi) \zeta_{3}+(2 \pi-1) \zeta_{4} \leq(2 \pi-1) \varpi_{1}+(2-2 \pi) \varpi_{2}, & \text { if } \pi>0.5 ; \\
(1-2 \pi) \zeta_{1}+(2 \pi) \zeta_{2} \leq(2 \pi) \varpi_{3}+(1-2 \pi) \varpi_{4}, & \text { if } \pi \leq 0.5 .\end{cases} \\
& \operatorname{Cr}\{\zeta \geq \tilde{\varpi}\} \geq \pi \Leftrightarrow \begin{cases}(2 \pi-1) \zeta_{1}+(2-2 \pi) \zeta_{2} \geq(2-2 \pi) \varpi_{3}+(2 \pi-1) \varpi_{4}, & \text { if } \pi>0.5 ; \\
(2 \pi) \zeta_{3}+(1-2 \pi) \zeta_{4} \geq(1-2 \pi) \varpi_{1}+(2 \pi) \varpi_{2}, & \text { if } \pi \leq 0.5 .\end{cases} \\
& \operatorname{Cr}\{\zeta \leq \varpi\} \geq \pi \Leftrightarrow \begin{cases}(2-2 \pi) \zeta_{3}+(2 \pi-1) \zeta_{4} \leq \varpi, & \text { if } \pi>0.5 ; \\
(1-2 \pi) \zeta_{1}+(2 \pi) \zeta_{2} \leq \varpi, & \text { if } \pi \leq 0.5 .\end{cases} \\
& \operatorname{Cr}\{\zeta \geq \varpi\} \geq \pi \Leftrightarrow \begin{cases}(2 \pi-1) \zeta_{1}+(2-2 \pi) \zeta_{2} \geq \varpi, & \text { if } \pi>0.5 ; \\
(2 \pi) \zeta_{3}+(1-2 \pi) \zeta_{4} \geq \varpi, & \text { if } \pi \leq 0.5 .\end{cases}
\end{aligned}
$$

\section{Appendix B. Fuzzy DEA model based on Possibility, Necessity and Credibility measures}

B.1. Fuzzy DEA model based on Possibility measure

$\operatorname{Max} \Theta$

$$
\begin{array}{ll}
\text { S.t. } & \sum_{r=1}^{s}\left((\alpha) y_{r p}^{3}+(1-\alpha) y_{r p}^{4}\right) u_{r} \geq \Theta \\
& \sum_{i=1}^{m}\left((1-\beta) x_{i p}^{1}+(\beta) x_{i p}^{2}\right) v_{i} \leq 1 \\
& \sum_{r=1}^{s}\left(\left(1-\delta_{j}\right) y_{r j}^{1}+\left(\delta_{j}\right) y_{r j}^{2}\right) u_{r}-\sum_{i=1}^{m}\left(\left(\delta_{j}\right) x_{i j}^{3}+\left(1-\delta_{j}\right) x_{i j}^{4}\right) v_{i} \leq 0, \quad \forall j \\
& u_{r}, v_{i} \geq 0, \quad \forall r, i
\end{array}
$$

B.2. Fuzzy DEA model based on Necessity measure

$\operatorname{Max} \Theta$

$$
\begin{array}{ll}
\text { S.t. } & \sum_{r=1}^{s}\left((\alpha) y_{r p}^{1}+(1-\alpha) y_{r p}^{2}\right) u_{r} \geq \Theta \\
& \sum_{i=1}^{m}\left((1-\beta) x_{i 0}^{3}+(\beta) x_{i 0}^{4}\right) v_{i} \leq 1 \\
& \sum_{r=1}^{s}\left(\left(1-\delta_{j}\right) y_{r j}^{3}+\left(\delta_{j}\right) y_{r j}^{4}\right) u_{r}-\sum_{i=1}^{m}\left(\left(\delta_{j}\right) x_{i j}^{1}+\left(1-\delta_{j}\right) x_{i j}^{2}\right) v_{i} \leq 0, \quad \forall j \\
& u_{r}, v_{i} \geq 0, \quad \forall r, i
\end{array}
$$


B.3. Fuzzy DEA model based on Credibility measure

$\operatorname{Max} \Theta$

S.t. $\sum_{r=1}^{s}\left((2 \alpha-1) y_{r p}^{1}+(2-2 \alpha) y_{r p}^{2}\right) u_{r} \geq \Theta-\Omega \Psi$

$$
\begin{aligned}
& \sum_{r=1}^{s}\left((2 \alpha) y_{r p}^{3}+(1-2 \alpha) y_{r p}^{4}\right) u_{r} \geq \Theta-\Omega(1-\Psi) \\
& \sum_{i=1}^{m}\left((2-2 \beta) x_{i p}^{3}+(2 \beta-1) x_{i p}^{4}\right) v_{i} \leq 1+\Omega \Phi \\
& \sum_{i=1}^{m}\left((1-2 \beta) x_{i p}^{1}+(2 \beta) x_{i p}^{2}\right) v_{i} \leq 1+\Omega(1-\Phi) \\
& \sum_{r=1}^{s}\left(\left(2-2 \delta_{j}\right) y_{r j}^{3}+\left(2 \delta_{j}-1\right) y_{r j}^{4}\right) u_{r}-\sum_{i=1}^{m}\left(\left(2 \delta_{j}-1\right) x_{i j}^{1}+\left(2-2 \delta_{j}\right) x_{i j}^{2}\right) v_{i} \leq \Omega \Upsilon_{j}, \quad \forall j \\
& \sum_{r=1}^{s}\left(\left(1-2 \delta_{j}\right) y_{r j}^{1}+\left(2 \delta_{j}\right) y_{r j}^{2}\right) u_{r}-\sum_{i=1}^{m}\left(\left(2 \delta_{j}\right) x_{i j}^{3}+\left(1-2 \delta_{j}\right) x_{i j}^{4}\right) v_{i} \leq \Omega\left(1-\Upsilon_{j}\right), \quad \forall j \\
& \alpha>0.5-\Omega \Psi \\
& \alpha \leq 0.5+\Omega(1-\Psi) \\
& \beta>0.5-\Omega \Phi \\
& \beta \leq 0.5+\Omega(1-\Phi) \\
& \delta_{j}>0.5-\Omega \Upsilon_{j}, \quad \forall j \\
& \delta_{j} \leq 0.5+\Omega\left(1-\Upsilon_{j}\right), \quad \forall j \\
& \Psi, \Phi, \Upsilon_{j} \in\{0,1\}, \quad \forall j \\
& u_{r}, v_{i} \geq 0, \quad \forall r, i
\end{aligned}
$$




\section{Appendix C. Adjustable fuzzy DEA model based on triangular fuzzy numbers}

$\operatorname{Max} \Theta$

$$
\begin{array}{ll}
\text { S.t. } & \sum_{r=1}^{s}\left(\left(\frac{\alpha-\xi}{1-\xi}\right) y_{r p}^{1}+\left(\frac{1-\alpha}{1-\xi}\right) y_{r p}^{2}\right) u_{r} \geq \Theta-\Omega \Psi \\
& \sum_{r=1}^{s}\left(\left(\frac{\alpha}{\lambda}\right) y_{r p}^{2}+\left(\frac{\lambda-\alpha}{\lambda}\right) y_{r p}^{3}\right) u_{r} \geq \Theta-\Omega(1-\Psi) \\
& \sum_{i=1}^{m}\left(\left(\frac{1-\beta}{1-\varphi}\right) x_{i p}^{2}+\left(\frac{\beta-\varphi}{1-\varphi}\right) x_{i p}^{3}\right) v_{i} \leq 1+\Omega \Phi \\
& \sum_{i=1}^{m}\left(\left(\frac{\varphi-\beta}{\varphi}\right) x_{i p}^{1}+\left(\frac{\beta}{\varphi}\right) x_{i p}^{2}\right) v_{i} \leq 1+\Omega(1-\Phi) \\
& \sum_{r=1}^{s}\left(\left(\frac{1-\delta_{j}}{1-\gamma}\right) y_{r j}^{2}+\left(\frac{\delta_{j}-\gamma}{1-\gamma}\right) y_{r j}^{3}\right) u_{r}-\sum_{i=1}^{m}\left(\left(\frac{\delta_{j}-\gamma}{1-\gamma}\right) x_{i j}^{1}+\left(\frac{1-\delta_{j}}{1-\gamma}\right) x_{i j}^{2}\right) v_{i} \leq \Omega \Upsilon_{j}, \quad \forall j \\
& u_{r}, v_{i} \geq 0, \forall r, i \\
& \delta_{j} \leq \gamma \leq \Upsilon_{j} \in\left\{\left(\left(\frac{\gamma-\delta_{j}}{\gamma}\right) y_{r j}^{1}+\left(\frac{\delta_{j}}{\gamma}\right) y_{r j}^{2}\right) u_{r}-\sum_{i=1}^{m}\left(\left(\frac{\delta_{j}}{\gamma}\right) x_{i j}^{2}+\left(\frac{\gamma-\delta_{j}}{\gamma}\right) x_{i j}^{3}\right) v_{i} \leq \Omega\left(1-\Upsilon_{j}\right), \forall j\right. \\
& \sum_{r=1}>\Upsilon_{j}, \forall j \\
& \alpha>\xi-\Omega \Psi
\end{array}
$$




\section{References}

Agarwal, S. (2014). Fuzzy Slack Based Measure of Data Envelopment Analysis: A Possibility Approach. In Proceedings of the Third International Conference on Soft Computing for Problem Solving (pp. 733-740). Springer, New Delhi.

Ahmadvand, S., \& Pishvaee, M. S. (2017). An efficient method for kidney allocation problem: a credibilitybased fuzzy common weights data envelopment analysis approach. Health Care Management Science, $1-17$.

Amirkhan, M., Didehkhani, H., Khalili-Damghani, K., \& Hafezalkotob, A. (2018). Mixed uncertainties in data envelopment analysis: A fuzzy-robust approach. Expert Systems with Applications, 103, 218-237.

Azadeh, A., \& Kokabi, R. (2016). Z-number DEA: A new possibilistic DEA in the context of Znumbers. Advanced engineering informatics, 30(3), 604-617.

Banker, R. D., Charnes, A., \& Cooper, W. W. (1984). Some models for estimating technical and scale inefficiencies in data envelopment analysis. Management Science, 30(9), 1078-1092.

Charnes, A., \& Cooper, W. W. (1959). Chance-constrained programming. Management Science, 6(1), 7379.

Charnes, A., Cooper, W. W., \& Rhodes, E. (1978). Measuring the efficiency of decision making units. European Journal of Operational Research, 2(6), 429-444.

Charnes, A., Cooper, W. W., Golany, B., Seiford, L., \& Stutz, J. (1985). Foundations of data envelopment analysis for Pareto-Koopmans efficient empirical production functions. Journal of Econometrics, 30(1-2), 91-107.

Cheng, G., Zervopoulos, P., \& Qian, Z. (2013). A variant of radial measure capable of dealing with negative inputs and outputs in data envelopment analysis. European Journal of Operational Research, 225(1), 100-105.

Dubois, D., \& Prade, H. (1978). Operations on fuzzy numbers. International Journal of Systems Science, 9(6), 613-626.

Dubois, D., \& Prade, H. (1988). H. Possibility Theory.

Emrouznejad, A., A. L. Anouze and E. Thanassoulis (2010). A semi-oriented radial measure for measuring the efficiency of decision making units with negative data, using DEA. European Journal of Operational Research 200(1): 297-304. 
Emrouznejad, A., \& Tavana, M. (Eds.). (2014). Performance Measurement with Fuzzy Data Envelopment Analysis. Springer Berlin.

Emrouznejad, A., G. L. Yang (2018). A survey and analysis of the first 40 years of scholarly literature in DEA: 1978-2016, Socio-Economic Planning Sciences, 61(1): 4-8.

Farrell, M. J. (1957). The measurement of productive efficiency. Journal of the Royal Statistical Society. Series A (General), 120(3), 253-290.

Garcia, P. A., \& Schirru, R. (2005). A fuzzy data envelopment analysis approach for FMEA. Progress in Nuclear Energy, 46(3-4), 359-373.

Guo, P., Tanaka, H., \& Inuiguchi, M. (2000). Self-organizing fuzzy aggregation models to rank the objects with multiple attributes. IEEE Transactions on Systems, Man, and Cybernetics-Part A: Systems and Humans, 30(5), 573-580.

Hatami-Marbini, A., Emrouznejad, A., \& Tavana, M. (2011). A taxonomy and review of the fuzzy data envelopment analysis literature: two decades in the making. European Journal of Operational Research, 214(3), 457-472.

Hatami-Marbini, A., Tavana, M., \& Emrouznejad, A. (2012). Productivity growth and efficiency measurements in fuzzy environments with an application to health care. International Journal of Fuzzy System Applications (IJFSA), 2(2), 1-35.

Heilpern, S. (1992). The expected value of a fuzzy number. Fuzzy sets and Systems, 47(1), 81-86.

Hossainzadeh, F., Jahanshahloo, G. R., Kodabakhshi, M., \& Moradi, F. (2011). A fuzzy chance constraint multi objective programming method in data envelopment analysis. African Journal of Business Management, 5(33), 12873.

Ji, A. B., Qiao, Y., \& Liu, C. (2019). Fuzzy DEA-based classifier and its applications in healthcare management. Health Care Management Science, 1-9.

Jiang, N., \& Yang, Y. (2007). A fuzzy chance-constrained DEA model based on Cr measure. International Journal of Business and Management, 2(2), 17-21.

Kahraman, C., \& Tolga, E. (1998). Data envelopment analysis using fuzzy concept. In Proceedings. 28th IEEE International Symposium on Multiple-Valued Logic (Cat. No. 98CB36138) (pp. 338-343).

Khodabakhshi, M., Gholami, Y., \& Kheirollahi, H. (2010). An additive model approach for estimating returns to scale in imprecise data envelopment analysis. Applied Mathematical Modelling, 34(5), 1247-1257. 
Lertworasirikul, S. (2002). Fuzzy Data Envelopment Analysis (DEA). Ph.D. Dissertation, Department of Industrial Engineering, North Carolina State University.

Lertworasirikul, S., Fang, S. C., Joines, J. A., \& Nuttle, H. L. (2002b). A Possibility Approach to Fuzzy Data Envelopment Analysis. Proceedings of the Joint Conference on Information Sciences, 6, 176179.

Lertworasirikul, S., Fang, S. C., Joines, J. A., \& Nuttle, H. L. (2003a). Fuzzy data envelopment analysis (DEA): a possibility approach. Fuzzy Sets and Systems, 139(2), 379-394.

Lertworasirikul, S., Fang, S. C., Joines, J., \& Nuttle, H. (2003c). Fuzzy data envelopment analysis: A credibility approach. Fuzzy Sets Based Heuristics for Optimization, 141-158.

Lertworasirikul, S., Fang, S. C., Nuttle, H. L. W., \& Joines, J. A. (2002a). Fuzzy data envelopment analysis. Proceedings of the 9th Bellman Continuum, Beijing, 342.

Lertworasirikul, S., Fang, S. C., Nuttle, H. L., \& Joines, J. A. (2003b). Fuzzy BCC model for data envelopment analysis. Fuzzy Optimization and Decision Making, 2(4), 337-358.

Lin, H. T. (2010). Personnel selection using analytic network process and fuzzy data envelopment analysis approaches. Computers \& Industrial Engineering, 59(4), 937-944.

Liu, B., \& Liu, Y. K. (2002). Expected value of fuzzy variable and fuzzy expected value models. IEEE Transactions on Fuzzy Systems, 10(4), 445-450.

Liu, S. T., \& Chuang, M. (2009). Fuzzy efficiency measures in fuzzy DEA/AR with application to university libraries. Expert Systems with Applications, 36(2), 1105-1113.

Nedeljković, R. R., \& Drenovac, D. (2012). Efficiency measurement of delivery post offices using fuzzy data envelopment analysis (Possibility approach). International Journal for Traffic and Transport Engineering, 2(1), 22-29.

O’Neill, L., Rauner, M., Heidenberger, K., \& Kraus, M. (2008). A cross-national comparison and taxonomy of DEA-based hospital efficiency studies. Socio-Economic Planning Sciences, 42(3), 158-189.

Omrani, H., Shafaat, K., \& Emrouznejad, A. (2018). An integrated fuzzy clustering cooperative game data envelopment analysis model with application in hospital efficiency. Expert Systems with Applications, 114, 615-628.

Payan, A. (2015). Common set of weights approach in fuzzy DEA with an application. Journal of Intelligent \& Fuzzy Systems, 29(1), 187-194. 
Payan, A., \& Shariff, M. (2013). Scrutiny Malmquist productivity index on fuzzy data by credibility theory with an application to social security organizations. Journal of Uncertain. Systems, 7(1), 36-49.

Peykani, P., Mohammadi, E., Pishvaee, M. S., Rostamy-Malkhalifeh, M., \& Jabbarzadeh, A. (2018). A novel fuzzy data envelopment analysis based on robust possibilistic programming: possibility, necessity and credibility-based approaches. RAIRO-Operations Research, 52(4), 1445-1463.

Peykani, P., Mohammadi, E., Rostamy-Malkhalifeh, M., \& Hosseinzadeh Lotfi, F. (2019). Fuzzy Data Envelopment Analysis Approach for Ranking of Stocks with an Application to Tehran Stock Exchange. Advances in Mathematical Finance and Applications, 4(1), 31-43.

Pishvaee, M. S., Razmi, J., \& Torabi, S. A. (2012). Robust possibilistic programming for socially responsible supply chain network design: A new approach. Fuzzy Sets and Systems, 206, 1-20.

Portela, M. S., Thanassoulis, E., \& Simpson, G. (2004). Negative data in DEA: A directional distance approach applied to bank branches. Journal of the Operational Research Society, 55(10), 1111-1121.

Qin, R., Liu, Y., Liu, Z., \& Wang, G. (2009). Modeling fuzzy DEA with Type-2 fuzzy variable coefficients. In International Symposium on Neural Networks (pp. 25-34). Springer, Berlin, Heidelberg.

Ruiz, J. L., \& Sirvent, I. (2017). Fuzzy cross-efficiency evaluation: a possibility approach. Fuzzy Optimization and Decision Making, 16(1), 111-126.

Tavana, M., Shiraz, R. K., Hatami-Marbini, A., Agrell, P. J., \& Paryab, K. (2013). Chance-constrained DEA models with random fuzzy inputs and outputs. Knowledge-Based Systems, 52, 32-52.

Wang, Y. M., \& Chin, K. S. (2011). Fuzzy data envelopment analysis: A fuzzy expected value approach. Expert Systems with Applications, 38(9), 11678-11685.

Wang, Y. M., Luo, Y., \& Liang, L. (2009). Fuzzy data envelopment analysis based upon fuzzy arithmetic with an application to performance assessment of manufacturing enterprises. Expert Systems with Applications, 36(3), 5205-5211.

Wen, M., \& Li, H. (2009). Fuzzy data envelopment analysis (DEA): Model and ranking method. Journal of Computational and Applied Mathematics, 223(2), 872-878.

Wen, M., Qin, Z., \& Kang, R. (2011). Sensitivity and stability analysis in fuzzy data envelopment analysis. Fuzzy Optimization and Decision Making, 10(1), 1-10.

Wen, M., You, C., \& Kang, R. (2010). A new ranking method to fuzzy data envelopment analysis. Computers \& Mathematics with Applications, 59(11), 3398-3404. 
Wen, M., Zhou, D., \& Lv, C. (2011). A fuzzy data envelopment analysis (DEA) model with credibility measure. Information-An International Interdisciplinary Journal, 14(6), 1947-1958.

Wu, D. D., Yang, Z., \& Liang, L. (2006). Efficiency analysis of cross-region bank branches using fuzzy data envelopment analysis. Applied Mathematics and Computation, 181(1), 271-281.

Xu, J., \& Zhou, X. (2011). Fuzzy-Like Multiple Objective Decision Making (Vol. 263). Berlin: Springer.

Zadeh, L. A. (1978). Fuzzy sets as a basis for a theory of possibility. Fuzzy Sets and Systems, 1(1), 3-28.

Zerafat Angiz L, M., Emrouznejad, A., \& Mustafa, A. (2010). Fuzzy assessment of performance of a decision making units using DEA: A non-radial approach. Expert Systems with Applications, 37(7), 5153-5157.

Zerafat Angiz L, M., Emrouznejad, A., \& Mustafa, A. (2012). Fuzzy data envelopment analysis: A discrete approach. Expert Systems with Applications, 39(3), 2263-2269.

Zhao, X., \& Yue, W. (2012). A multi-subsystem fuzzy DEA model with its application in mutual funds management companies' competence evaluation. Procedia Computer Science, 1(1), 2469-2478. 


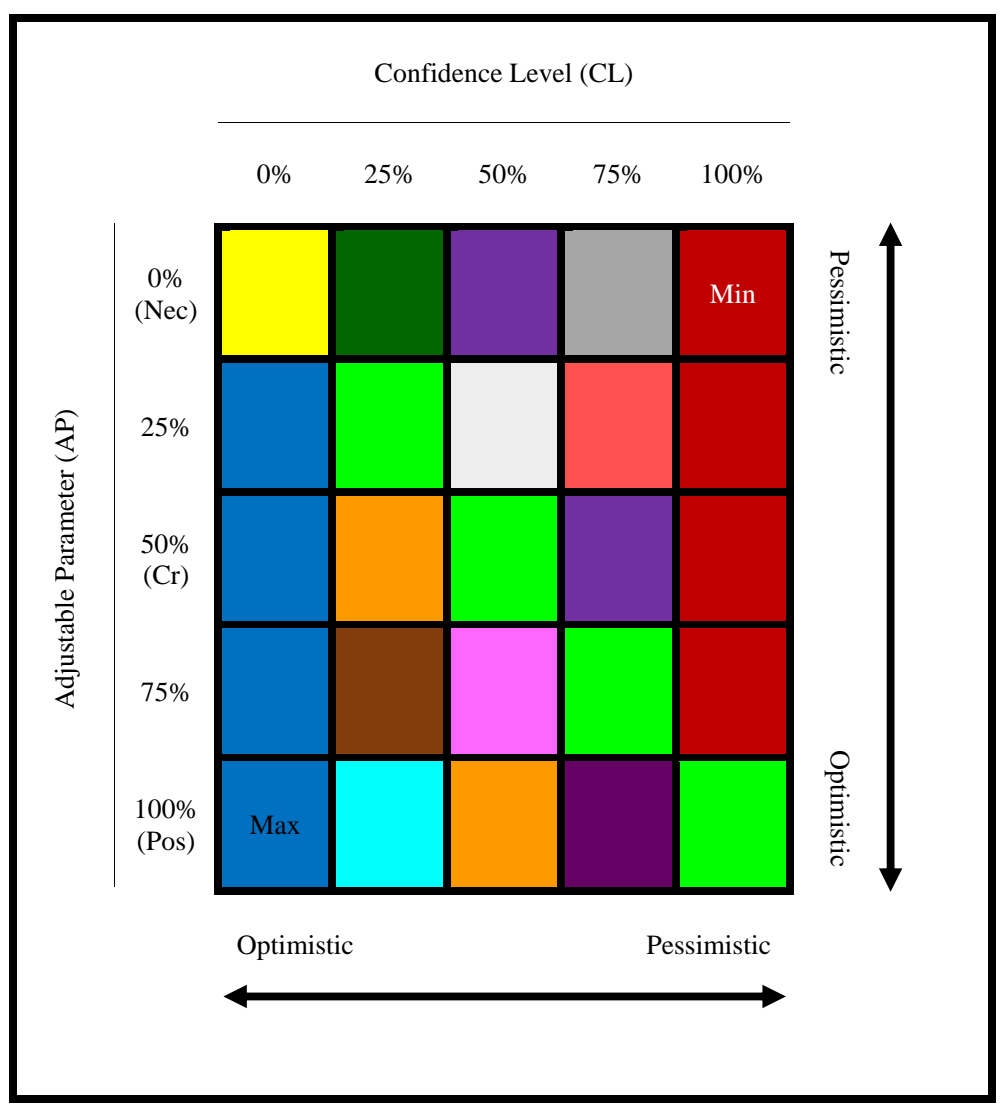

Figure 1: Graphical relations extracted from result of AFDEA Model

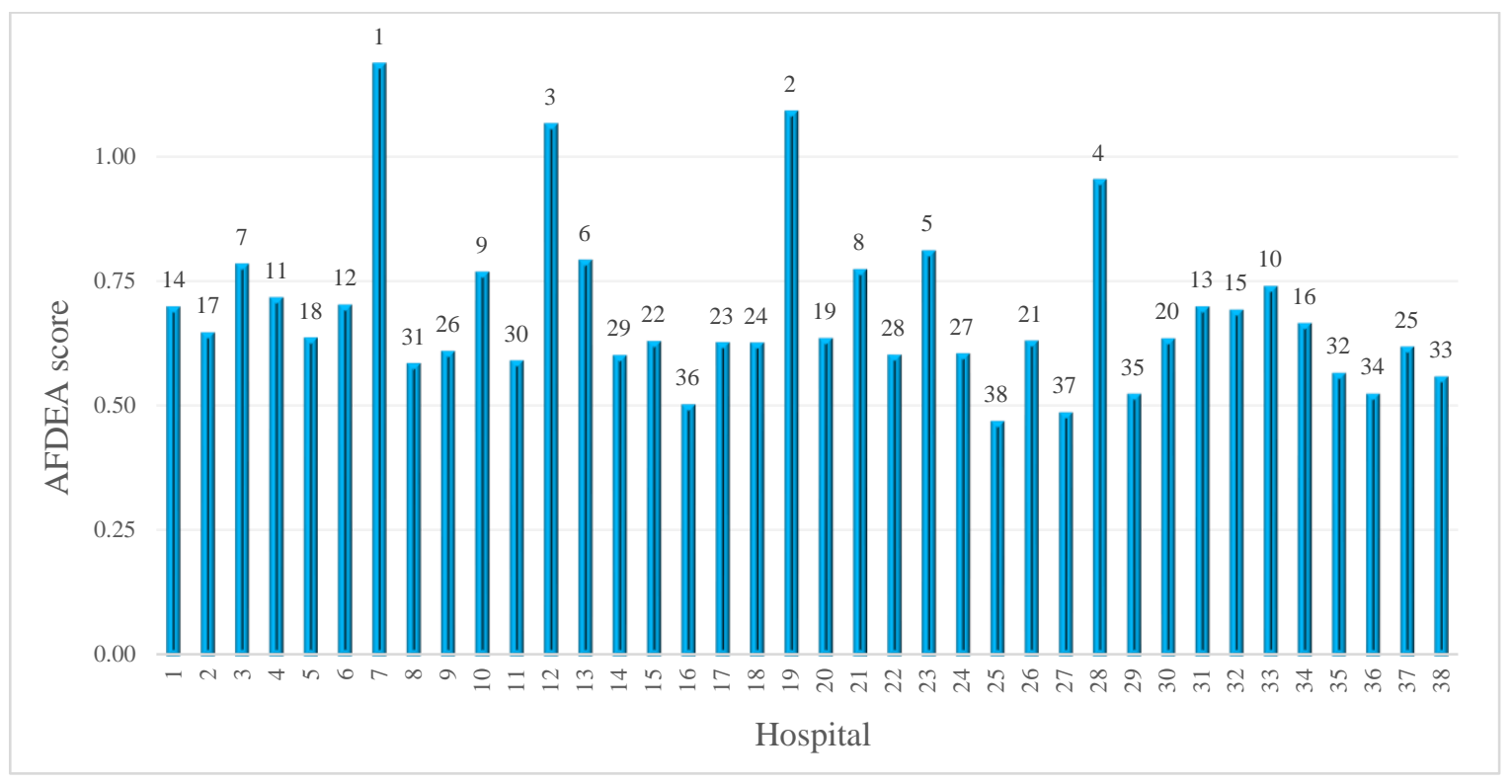

Figure 2: The average AFDEA results and ranking of all Hospitals 


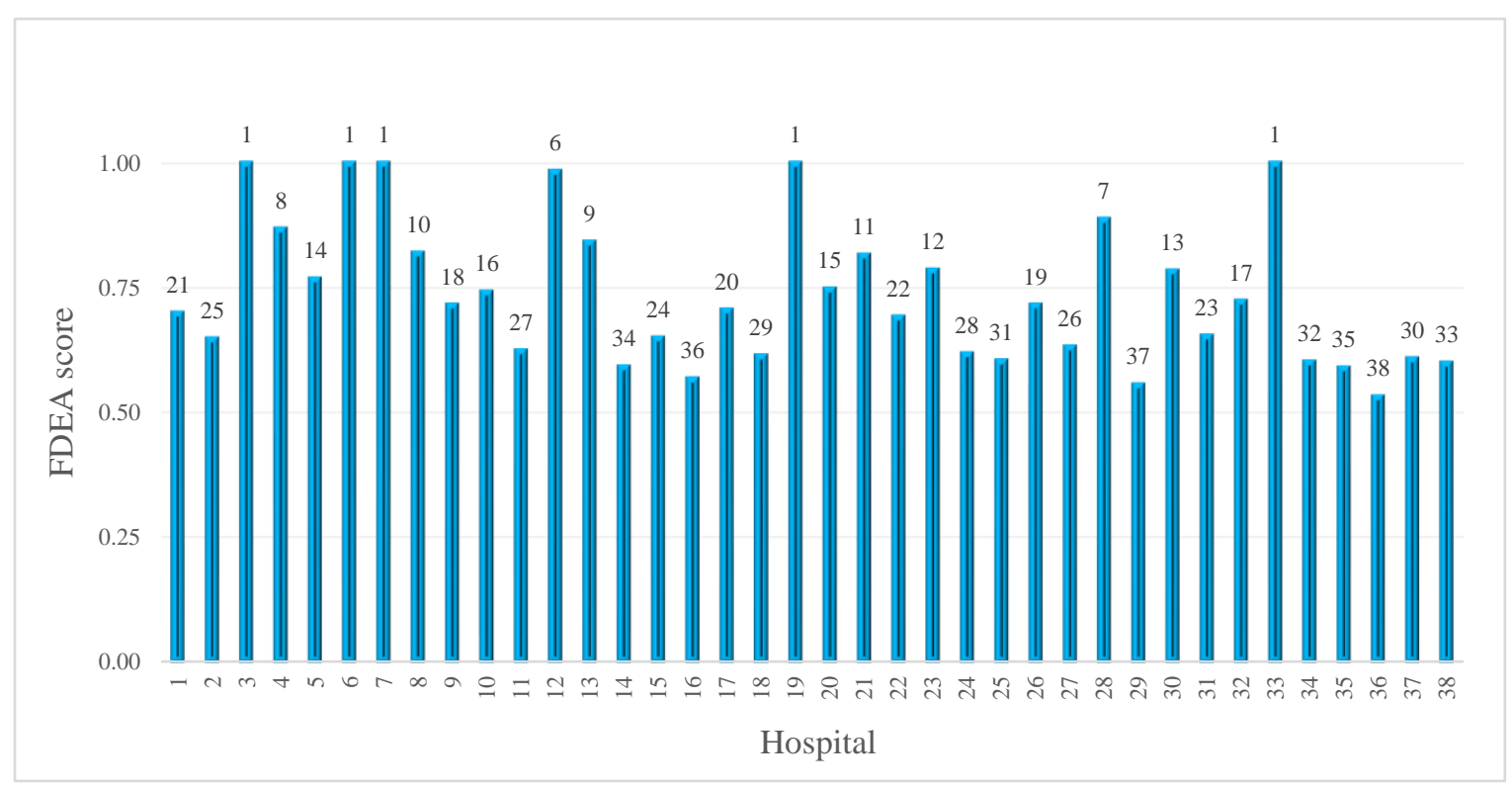

Figure 3: The average FDEA results and ranking of all Hospitals

Table 1: Data of five DMUs with two fuzzy inputs and two fuzzy outputs

\begin{tabular}{|c|c|c|c|c|}
\hline \multirow{2}{*}{ DMUs } & \multicolumn{2}{|c|}{ Inputs } & \multicolumn{2}{|c|}{ Outputs } \\
\hline & I (1) & $\mathrm{I}(2)$ & $\mathrm{U}(1)$ & $\mathrm{U}(2)$ \\
\hline DMU 01 & $(3.25,3.75,4.25,4.75)$ & $(2.25,2.5,2.75,3)$ & $(1,2,3,4)$ & $(4,4.5,5,5.5)$ \\
\hline DMU 02 & $(2,4,6,8)$ & $(4,4.5,5,5.5)$ & $(0.5,1,1.5,2)$ & $(2,3,4,5)$ \\
\hline DMU 03 & $(2.25,2.75,3.25,3.75)$ & $(2,3,4,5)$ & $(1,3,5,7)$ & $(1.5,2.5,3.5,4.5)$ \\
\hline DMU 04 & $(3.5,4.5,5.5,6.5)$ & $(4.5,5,5.5,6)$ & $(1.5,2,2.5,3)$ & $(0.25,0.5,0.75,1)$ \\
\hline DMU 05 & $(0.5,1,1.5,2)$ & $(1.5,1.75,2,2.25)$ & $(3,4,5,6)$ & $(2,2.75,3.5,4.25)$ \\
\hline
\end{tabular}


Table 2: Results of AFDEA model for five DMUs

\begin{tabular}{|c|c|c|c|c|c|c|c|}
\hline \multirow{7}{*}{ 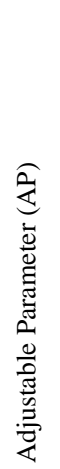 } & & \multicolumn{5}{|c|}{ Confidence Level (CL) } & \multirow{2}{*}{ DMUs } \\
\hline & & $0 \%$ & $25 \%$ & $50 \%$ & $75 \%$ & $100 \%$ & \\
\hline & \multirow{5}{*}{$8_{0}^{\circ}$} & 0.82 & 0.71 & 0.62 & 0.54 & 0.47 & DMU 01 \\
\hline & & 0.30 & 0.25 & 0.20 & 0.16 & 0.13 & DMU 02 \\
\hline & & 0.31 & 0.24 & 0.19 & 0.14 & 0.11 & DMU 03 \\
\hline & & 0.13 & 0.11 & 0.09 & 0.08 & 0.06 & DMU 04 \\
\hline & & 0.70 & 0.58 & 0.49 & 0.40 & 0.33 & DMU 05 \\
\hline & \multirow{5}{*}{$\stackrel{80}{2}$} & 2.18 & 1.26 & 0.68 & 0.57 & 0.47 & DMU 01 \\
\hline & & 2.50 & 0.63 & 0.23 & 0.17 & 0.13 & DMU 02 \\
\hline & & 2.63 & 0.85 & 0.22 & 0.16 & 0.11 & DMU 03 \\
\hline & & 0.57 & 0.25 & 0.10 & 0.08 & 0.06 & DMU 04 \\
\hline & & 8.50 & 1.91 & 0.55 & 0.43 & 0.33 & DMU 05 \\
\hline & \multirow{5}{*}{$\begin{array}{l}0 \\
\text { ô } \\
n\end{array}$} & 2.18 & 1.63 & 1.26 & 0.62 & 0.47 & DMU 01 \\
\hline & & 2.50 & 1.11 & 0.63 & 0.20 & 0.13 & DMU 02 \\
\hline & & 2.63 & 1.46 & 0.85 & 0.19 & 0.11 & DMU 03 \\
\hline & & 0.57 & 0.35 & 0.25 & 0.09 & 0.06 & DMU 04 \\
\hline & & 8.50 & 3.81 & 1.91 & 0.49 & 0.33 & DMU 05 \\
\hline & \multirow{5}{*}{$\begin{array}{l}\frac{8}{2} \\
i\end{array}$} & 2.18 & 1.79 & 1.49 & 1.26 & 0.47 & DMU 01 \\
\hline & & 2.50 & 1.43 & 0.87 & 0.63 & 0.13 & DMU 02 \\
\hline & & 2.63 & 1.76 & 1.21 & 0.85 & 0.11 & DMU 03 \\
\hline & & 0.57 & 0.41 & 0.31 & 0.25 & 0.06 & DMU 04 \\
\hline & & 8.50 & 4.89 & 3.00 & 1.91 & 0.33 & DMU 05 \\
\hline & \multirow{5}{*}{ ๕̊ } & 2.18 & 1.88 & 1.63 & 1.43 & 1.26 & DMU 01 \\
\hline & & 2.50 & 1.63 & 1.11 & 0.78 & 0.63 & DMU 02 \\
\hline & & 2.63 & 1.94 & 1.46 & 1.10 & 0.85 & DMU 03 \\
\hline & & 0.57 & 0.44 & 0.35 & 0.30 & 0.25 & DMU 04 \\
\hline & & 8.50 & 5.57 & 3.81 & 2.67 & 1.91 & DMU 05 \\
\hline
\end{tabular}


Table 3: Crisp data and results for five DMUs based on CCR model

\begin{tabular}{|c|c|c|c|c|c|c|}
\hline \multirow{2}{*}{ DMUs } & \multicolumn{2}{|c|}{ Inputs } & \multicolumn{2}{|c|}{ Outputs } & \multirow{2}{*}{ Efficiency Score } & \multirow{2}{*}{ Ranking } \\
\hline & $\mathrm{I}(1)$ & $\mathrm{I}(2)$ & $\mathrm{U}(1)$ & $\mathrm{U}(2)$ & & \\
\hline DMU 01 & 4 & 2.625 & 2.5 & 4.75 & 1.00 & 1 \\
\hline DMU 02 & 5 & 4.75 & 1.25 & 3.5 & 0.43 & 4 \\
\hline DMU 03 & 3 & 3.5 & 4 & 3 & 0.51 & 3 \\
\hline DMU 04 & 5 & 5.25 & 2.25 & 0.625 & 0.18 & 5 \\
\hline DMU 05 & 1.25 & 1.875 & 4.5 & 3.125 & 1.00 & 1 \\
\hline
\end{tabular}

Table 4: The inputs and outputs of AFDEA model for hospital efficiency measurement

\begin{tabular}{|c|c|c|c|}
\hline \multicolumn{2}{|l|}{ Inputs } & \multicolumn{2}{|l|}{ Outputs } \\
\hline Title & Symbol & Title & Symbol \\
\hline Number of Beds & $\mathrm{I}(1)$ & Number of Outpatient Department Visits & $\mathrm{O}(1)$ \\
\hline Labor-Related Expenses & I (2) & Number of Inpatient Department Admissions & $\mathrm{O}(2)$ \\
\hline Patient Care Supplies and Other Expenses & $\mathrm{I}(3)$ & Overall Patient Satisfaction & $\mathrm{O}(3)$ \\
\hline
\end{tabular}

Table 5: Data for 38 hospitals in East Virginia Department of Health and Human Services, USA

\begin{tabular}{|c|c|c|c|c|c|c|}
\hline \multirow{2}{*}{ Hospitals } & \multicolumn{3}{|c|}{ Inputs } & \multicolumn{3}{|c|}{ Outputs } \\
\hline & I (1) & $\mathrm{I}(2)$ & I (3) & $\mathrm{O}(1)$ & $\mathrm{O}(2)$ & $\mathrm{O}(3)$ \\
\hline 1 & 83 & $\$ 5,428,903$ & $\$ 3,142,311$ & 42,859 & 5,274 & ML \\
\hline 2 & 78 & $\$ 6,583,333$ & $\$ 4,126,127$ & 48,367 & 5,268 & M \\
\hline 3 & 54 & $\$ 5,495,517$ & $\$ 2,177,965$ & 55,606 & 7,302 & $\mathrm{~L}$ \\
\hline 4 & 80 & $\$ 6,426,532$ & $\$ 3,501,847$ & 48,879 & 7,077 & MH \\
\hline 5 & 75 & $\$ 6,782,869$ & $\$ 2,894,877$ & 46,801 & 6,593 & ML \\
\hline 6 & 87 & $\$ 5,491,546$ & $\$ 2,565,741$ & 57,977 & 7,574 & VL \\
\hline 7 & 58 & $\$ 3,778,001$ & $\$ 2,036,342$ & 57,787 & 5,264 & $\mathrm{MH}$ \\
\hline 8 & 71 & $\$ 6,999,241$ & $\$ 3,036,959$ & 70,031 & 6,090 & VL \\
\hline 9 & 76 & $\$ 7,942,581$ & $\$ 3,982,119$ & 62,102 & 5,157 & M \\
\hline 10 & 80 & $\$ 7,473,486$ & $\$ 4,741,523$ & 52,940 & 3,476 & VH \\
\hline 11 & 78 & $\$ 6,698,820$ & $\$ 3,770,352$ & 40,055 & 5,611 & $\mathrm{~L}$ \\
\hline 12 & 60 & $\$ 4,293,792$ & $\$ 2,110,921$ & 56,555 & 5,586 & MH \\
\hline 13 & 78 & $\$ 7,199,197$ & $\$ 3,166,796$ & 64,143 & 5,170 & $\mathrm{H}$ \\
\hline 14 & 69 & $\$ 7,608,522$ & $\$ 3,400,052$ & 48,890 & 4,456 & $\mathrm{~L}$ \\
\hline 15 & 80 & $\$ 6,775,716$ & $\$ 3,495,441$ & 54,330 & 4,774 & M \\
\hline 16 & 81 & $\$ 8,716,008$ & $\$ 3,530,795$ & 46,305 & 6,125 & VL \\
\hline 17 & 77 & $\$ 7,237,227$ & $\$ 3,524,780$ & 44,564 & 6,218 & $\mathrm{M}$ \\
\hline 18 & 87 & $\$ 7,592,595$ & $\$ 4,701,414$ & 52,283 & 3,798 & MH \\
\hline 19 & 49 & $\$ 5,604,079$ & $\$ 2,696,243$ & 41,782 & 4,814 & VH \\
\hline 20 & 64 & $\$ 6,721,746$ & $\$ 2,760,717$ & 38,308 & 6,418 & VL \\
\hline 21 & 90 & $\$ 5,147,491$ & $\$ 2,618,025$ & 42,211 & 5,618 & $\mathrm{M}$ \\
\hline 22 & 84 & $\$ 8,416,341$ & $\$ 4,086,333$ & 41,346 & 6,705 & MH \\
\hline 23 & 81 & $\$ 6,945,228$ & $\$ 4,312,511$ & 50,619 & 4,783 & VH \\
\hline 24 & 81 & $\$ 7,340,542$ & $\$ 3,907,518$ & 47,010 & 5,476 & M \\
\hline 25 & 89 & $\$ 9,202,308$ & $\$ 4,637,745$ & 67,091 & 5,179 & $\mathrm{~L}$ \\
\hline 26 & 79 & $\$ 6,861,558$ & $\$ 3,445,030$ & 60,469 & 5,515 & M \\
\hline 27 & 86 & $\$ 8,359,115$ & $\$ 3,718,448$ & 61,267 & 6,225 & VL \\
\hline 28 & 70 & $\$ 7,636,593$ & $\$ 2,870,895$ & 47,437 & 6,843 & VH \\
\hline 29 & 81 & $\$ 7,939,155$ & $\$ 4,219,269$ & 46,235 & 5,620 & $\mathrm{~L}$ \\
\hline 30 & 80 & $\$ 6,310,243$ & $\$ 3,439,974$ & 63,992 & 6,538 & ML \\
\hline 31 & 78 & $\$ 6,793,294$ & $\$ 4,404,172$ & 42,032 & 4,821 & MH \\
\hline 32 & 86 & $\$ 7,517,868$ & $\$ 4,652,596$ & 49,402 & 6,238 & $\mathrm{H}$ \\
\hline 33 & 55 & $\$ 6,808,131$ & $\$ 2,303,569$ & 78,483 & 5,866 & VL \\
\hline 34 & 80 & $\$ 6,109,813$ & $\$ 3,449,003$ & 35,649 & 4,495 & $\mathrm{M}$ \\
\hline 35 & 82 & $\$ 7,517,663$ & $\$ 4,054,654$ & 51,891 & 4,996 & ML \\
\hline 36 & 79 & $\$ 7,887,497$ & $\$ 3,281,593$ & 49,168 & 4,641 & VL \\
\hline 37 & 85 & $\$ 9,046,154$ & $\$ 4,696,585$ & 50,796 & 5,160 & $\mathrm{H}$ \\
\hline 38 & 85 & $\$ 7,033,971$ & $\$ 4,098,183$ & 56,017 & 5,017 & $\mathrm{~L}$ \\
\hline
\end{tabular}


Table 6: The linguistic variables and their associated TFN

\begin{tabular}{cc}
\hline Linguistic Variable & Trapezoidal Fuzzy Number \\
\hline Very low $(\mathrm{VL})$ & $(0,0,0.1,0.2)$ \\
Low $(\mathrm{L})$ & $(0.1,0.2,0.2,0.3)$ \\
Medium low $(\mathrm{ML})$ & $(0.2,0.3,0.4,0.5)$ \\
Medium $(\mathrm{M})$ & $(0.4,0.5,0.5,0.6)$ \\
Medium high $(\mathrm{MH})$ & $(0.5,0.6,0.7,0.8)$ \\
High $(\mathrm{H})$ & $(0.7,0.8,0.8,0.9)$ \\
Very high $(\mathrm{VH})$ & $(0.8,0.9,0.9,1)$ \\
\hline
\end{tabular}

Table 7: Results of AFDEA model for AP = 0\% (Necessity measure)

\begin{tabular}{|c|c|c|c|c|c|}
\hline \multirow{2}{*}{ Hospitals } & \multicolumn{5}{|c|}{$\alpha$-level } \\
\hline & $0 \%$ & $25 \%$ & $50 \%$ & $75 \%$ & $100 \%$ \\
\hline 1 & 0.70 & 0.70 & 0.70 & 0.70 & 0.70 \\
\hline 2 & 0.63 & 0.62 & 0.61 & 0.59 & 0.59 \\
\hline 3 & 0.76 & 0.75 & 0.75 & 0.75 & 0.75 \\
\hline 4 & 0.65 & 0.64 & 0.63 & 0.62 & 0.60 \\
\hline 5 & 0.59 & 0.58 & 0.58 & 0.58 & 0.58 \\
\hline 6 & 0.70 & 0.70 & 0.70 & 0.70 & 0.70 \\
\hline 7 & 1.00 & 1.00 & 1.00 & 1.00 & 1.00 \\
\hline 8 & 0.58 & 0.58 & 0.58 & 0.58 & 0.58 \\
\hline 9 & 0.60 & 0.59 & 0.58 & 0.57 & 0.56 \\
\hline 10 & 0.72 & 0.69 & 0.67 & 0.66 & 0.65 \\
\hline 11 & 0.58 & 0.58 & 0.58 & 0.58 & 0.58 \\
\hline 12 & 0.92 & 0.91 & 0.89 & 0.89 & 0.89 \\
\hline 13 & 0.74 & 0.71 & 0.70 & 0.68 & 0.66 \\
\hline 14 & 0.59 & 0.58 & 0.58 & 0.58 & 0.58 \\
\hline 15 & 0.62 & 0.60 & 0.59 & 0.58 & 0.58 \\
\hline 16 & 0.49 & 0.49 & 0.49 & 0.49 & 0.49 \\
\hline 17 & 0.62 & 0.61 & 0.59 & 0.58 & 0.57 \\
\hline 18 & 0.59 & 0.57 & 0.56 & 0.55 & 0.54 \\
\hline 19 & 1.06 & 1.05 & 1.03 & 1.01 & 0.99 \\
\hline 20 & 0.62 & 0.62 & 0.62 & 0.62 & 0.62 \\
\hline 21 & 0.74 & 0.74 & 0.74 & 0.74 & 0.74 \\
\hline 22 & 0.58 & 0.57 & 0.56 & 0.54 & 0.53 \\
\hline 23 & 0.76 & 0.71 & 0.69 & 0.67 & 0.66 \\
\hline 24 & 0.60 & 0.58 & 0.57 & 0.56 & 0.55 \\
\hline 25 & 0.46 & 0.45 & 0.45 & 0.45 & 0.45 \\
\hline 26 & 0.62 & 0.61 & 0.59 & 0.58 & 0.57 \\
\hline 27 & 0.48 & 0.48 & 0.48 & 0.48 & 0.48 \\
\hline 28 & 0.92 & 0.87 & 0.82 & 0.79 & 0.77 \\
\hline 29 & 0.51 & 0.51 & 0.51 & 0.51 & 0.51 \\
\hline 30 & 0.61 & 0.61 & 0.61 & 0.61 & 0.61 \\
\hline 31 & 0.65 & 0.64 & 0.63 & 0.62 & 0.60 \\
\hline 32 & 0.64 & 0.63 & 0.62 & 0.61 & 0.59 \\
\hline 33 & 0.73 & 0.73 & 0.73 & 0.73 & 0.73 \\
\hline 34 & 0.64 & 0.63 & 0.63 & 0.63 & 0.63 \\
\hline 35 & 0.53 & 0.52 & 0.52 & 0.52 & 0.52 \\
\hline 36 & 0.52 & 0.52 & 0.52 & 0.52 & 0.52 \\
\hline 37 & 0.61 & 0.59 & 0.58 & 0.57 & 0.56 \\
\hline 38 & 0.55 & 0.55 & 0.55 & 0.55 & 0.55 \\
\hline
\end{tabular}


Table 8: Results of AFDEA model for AP $=25 \%$

\begin{tabular}{|c|c|c|c|c|c|}
\hline \multirow{2}{*}{ Hospitals } & \multicolumn{5}{|c|}{$\alpha$-level } \\
\hline & $0 \%$ & $25 \%$ & $50 \%$ & $75 \%$ & $100 \%$ \\
\hline 1 & 0.70 & 0.70 & 0.70 & 0.70 & 0.70 \\
\hline 2 & 0.70 & 0.65 & 0.62 & 0.60 & 0.59 \\
\hline 3 & 0.85 & 0.77 & 0.75 & 0.75 & 0.75 \\
\hline 4 & 0.88 & 0.70 & 0.64 & 0.62 & 0.60 \\
\hline 5 & 0.71 & 0.64 & 0.58 & 0.58 & 0.58 \\
\hline 6 & 0.70 & 0.70 & 0.70 & 0.70 & 0.70 \\
\hline 7 & 1.50 & 1.16 & 1.00 & 1.00 & 1.00 \\
\hline 8 & 0.60 & 0.58 & 0.58 & 0.58 & 0.58 \\
\hline 9 & 0.66 & 0.60 & 0.59 & 0.57 & 0.56 \\
\hline 10 & 0.94 & 0.75 & 0.68 & 0.67 & 0.65 \\
\hline 11 & 0.61 & 0.58 & 0.58 & 0.58 & 0.58 \\
\hline 12 & 1.32 & 1.07 & 0.90 & 0.89 & 0.89 \\
\hline 13 & 0.96 & 0.79 & 0.71 & 0.69 & 0.66 \\
\hline 14 & 0.63 & 0.59 & 0.58 & 0.58 & 0.58 \\
\hline 15 & 0.69 & 0.63 & 0.60 & 0.58 & 0.58 \\
\hline 16 & 0.52 & 0.49 & 0.49 & 0.49 & 0.49 \\
\hline 17 & 0.68 & 0.63 & 0.60 & 0.58 & 0.57 \\
\hline 18 & 0.75 & 0.62 & 0.57 & 0.55 & 0.54 \\
\hline 19 & 1.25 & 1.06 & 1.04 & 1.02 & 0.99 \\
\hline 20 & 0.66 & 0.62 & 0.62 & 0.62 & 0.62 \\
\hline 21 & 0.87 & 0.74 & 0.74 & 0.74 & 0.74 \\
\hline 22 & 0.68 & 0.61 & 0.56 & 0.55 & 0.53 \\
\hline 23 & 1.01 & 0.81 & 0.70 & 0.68 & 0.66 \\
\hline 24 & 0.66 & 0.60 & 0.58 & 0.56 & 0.55 \\
\hline 25 & 0.49 & 0.46 & 0.45 & 0.45 & 0.45 \\
\hline 26 & 0.69 & 0.63 & 0.60 & 0.59 & 0.57 \\
\hline 27 & 0.50 & 0.48 & 0.48 & 0.48 & 0.48 \\
\hline 28 & 1.17 & 0.95 & 0.85 & 0.80 & 0.77 \\
\hline 29 & 0.55 & 0.51 & 0.51 & 0.51 & 0.51 \\
\hline 30 & 0.68 & 0.62 & 0.61 & 0.61 & 0.61 \\
\hline 31 & 0.83 & 0.70 & 0.64 & 0.62 & 0.60 \\
\hline 32 & 0.84 & 0.67 & 0.63 & 0.61 & 0.59 \\
\hline 33 & 0.77 & 0.73 & 0.73 & 0.73 & 0.73 \\
\hline 34 & 0.72 & 0.66 & 0.63 & 0.63 & 0.63 \\
\hline 35 & 0.62 & 0.57 & 0.52 & 0.52 & 0.52 \\
\hline 36 & 0.54 & 0.52 & 0.52 & 0.52 & 0.52 \\
\hline 37 & 0.70 & 0.61 & 0.59 & 0.57 & 0.56 \\
\hline 38 & 0.57 & 0.55 & 0.55 & 0.55 & 0.55 \\
\hline
\end{tabular}


Table 9: Results of AFDEA model for AP $=50 \%$ (Credibility measure)

\begin{tabular}{|c|c|c|c|c|c|}
\hline \multirow{2}{*}{ Hospitals } & \multicolumn{5}{|c|}{$\alpha$-level } \\
\hline & $0 \%$ & $25 \%$ & $50 \%$ & $75 \%$ & $100 \%$ \\
\hline 1 & 0.70 & 0.70 & 0.70 & 0.70 & 0.70 \\
\hline 2 & 0.70 & 0.67 & 0.65 & 0.61 & 0.59 \\
\hline 3 & 0.85 & 0.81 & 0.77 & 0.75 & 0.75 \\
\hline 4 & 0.88 & 0.78 & 0.70 & 0.63 & 0.60 \\
\hline 5 & 0.71 & 0.68 & 0.64 & 0.58 & 0.58 \\
\hline 6 & 0.70 & 0.70 & 0.70 & 0.70 & 0.70 \\
\hline 7 & 1.50 & 1.33 & 1.16 & 1.00 & 1.00 \\
\hline 8 & 0.60 & 0.58 & 0.58 & 0.58 & 0.58 \\
\hline 9 & 0.66 & 0.63 & 0.60 & 0.58 & 0.56 \\
\hline 10 & 0.94 & 0.84 & 0.75 & 0.67 & 0.65 \\
\hline 11 & 0.61 & 0.58 & 0.58 & 0.58 & 0.58 \\
\hline 12 & 1.32 & 1.19 & 1.07 & 0.89 & 0.89 \\
\hline 13 & 0.96 & 0.86 & 0.79 & 0.70 & 0.66 \\
\hline 14 & 0.63 & 0.61 & 0.59 & 0.58 & 0.58 \\
\hline 15 & 0.69 & 0.66 & 0.63 & 0.59 & 0.58 \\
\hline 16 & 0.52 & 0.50 & 0.49 & 0.49 & 0.49 \\
\hline 17 & 0.68 & 0.65 & 0.63 & 0.59 & 0.57 \\
\hline 18 & 0.75 & 0.66 & 0.62 & 0.56 & 0.54 \\
\hline 19 & 1.25 & 1.12 & 1.06 & 1.03 & 0.99 \\
\hline 20 & 0.66 & 0.64 & 0.62 & 0.62 & 0.62 \\
\hline 21 & 0.87 & 0.78 & 0.74 & 0.74 & 0.74 \\
\hline 22 & 0.68 & 0.63 & 0.61 & 0.56 & 0.53 \\
\hline 23 & 1.01 & 0.90 & 0.81 & 0.69 & 0.66 \\
\hline 24 & 0.66 & 0.63 & 0.60 & 0.57 & 0.55 \\
\hline 25 & 0.49 & 0.48 & 0.46 & 0.45 & 0.45 \\
\hline 26 & 0.69 & 0.66 & 0.63 & 0.59 & 0.57 \\
\hline 27 & 0.50 & 0.48 & 0.48 & 0.48 & 0.48 \\
\hline 28 & 1.17 & 1.05 & 0.95 & 0.82 & 0.77 \\
\hline 29 & 0.55 & 0.53 & 0.51 & 0.51 & 0.51 \\
\hline 30 & 0.68 & 0.65 & 0.62 & 0.61 & 0.61 \\
\hline 31 & 0.83 & 0.74 & 0.70 & 0.63 & 0.60 \\
\hline 32 & 0.84 & 0.75 & 0.67 & 0.62 & 0.59 \\
\hline 33 & 0.77 & 0.74 & 0.73 & 0.73 & 0.73 \\
\hline 34 & 0.72 & 0.68 & 0.66 & 0.63 & 0.63 \\
\hline 35 & 0.62 & 0.59 & 0.57 & 0.52 & 0.52 \\
\hline 36 & 0.54 & 0.52 & 0.52 & 0.52 & 0.52 \\
\hline 37 & 0.70 & 0.63 & 0.61 & 0.58 & 0.56 \\
\hline 38 & 0.57 & 0.55 & 0.55 & 0.55 & 0.55 \\
\hline
\end{tabular}


Table 10: Results of AFDEA model for AP $=75 \%$

\begin{tabular}{|c|c|c|c|c|c|}
\hline \multirow{2}{*}{ Hospitals } & \multicolumn{5}{|c|}{$\alpha$-level } \\
\hline & $0 \%$ & $25 \%$ & $50 \%$ & $75 \%$ & $100 \%$ \\
\hline 1 & 0.70 & 0.68 & 0.66 & 0.70 & 0.70 \\
\hline 2 & 0.70 & 0.68 & 0.66 & 0.65 & 0.59 \\
\hline 3 & 0.85 & 0.82 & 0.79 & 0.77 & 0.75 \\
\hline 4 & 0.88 & 0.81 & 0.75 & 0.70 & 0.60 \\
\hline 5 & 0.71 & 0.69 & 0.66 & 0.64 & 0.58 \\
\hline 6 & 0.70 & 0.70 & 0.70 & 0.70 & 0.70 \\
\hline 7 & 1.50 & 1.38 & 1.27 & 1.16 & 1.00 \\
\hline 8 & 0.60 & 0.59 & 0.58 & 0.58 & 0.58 \\
\hline 9 & 0.66 & 0.64 & 0.62 & 0.60 & 0.56 \\
\hline 10 & 0.94 & 0.87 & 0.81 & 0.75 & 0.65 \\
\hline 11 & 0.61 & 0.59 & 0.58 & 0.58 & 0.58 \\
\hline 12 & 1.32 & 1.23 & 1.15 & 1.07 & 0.89 \\
\hline 13 & 0.96 & 0.89 & 0.84 & 0.79 & 0.66 \\
\hline 14 & 0.63 & 0.62 & 0.61 & 0.59 & 0.58 \\
\hline 15 & 0.69 & 0.67 & 0.65 & 0.63 & 0.58 \\
\hline 16 & 0.52 & 0.51 & 0.50 & 0.49 & 0.49 \\
\hline 17 & 0.68 & 0.66 & 0.64 & 0.63 & 0.57 \\
\hline 18 & 0.75 & 0.69 & 0.64 & 0.62 & 0.54 \\
\hline 19 & 1.25 & 1.16 & 1.09 & 1.06 & 0.99 \\
\hline 20 & 0.66 & 0.64 & 0.63 & 0.62 & 0.62 \\
\hline 21 & 0.87 & 0.81 & 0.76 & 0.74 & 0.74 \\
\hline 22 & 0.68 & 0.64 & 0.62 & 0.61 & 0.53 \\
\hline 23 & 1.01 & 0.94 & 0.87 & 0.81 & 0.66 \\
\hline 24 & 0.66 & 0.64 & 0.62 & 0.60 & 0.55 \\
\hline 25 & 0.49 & 0.48 & 0.47 & 0.46 & 0.45 \\
\hline 26 & 0.69 & 0.67 & 0.65 & 0.63 & 0.57 \\
\hline 27 & 0.50 & 0.49 & 0.48 & 0.48 & 0.48 \\
\hline 28 & 1.17 & 1.09 & 1.01 & 0.95 & 0.77 \\
\hline 29 & 0.55 & 0.54 & 0.52 & 0.51 & 0.51 \\
\hline 30 & 0.68 & 0.66 & 0.64 & 0.62 & 0.61 \\
\hline 31 & 0.83 & 0.77 & 0.72 & 0.70 & 0.60 \\
\hline 32 & 0.84 & 0.78 & 0.72 & 0.67 & 0.59 \\
\hline 33 & 0.77 & 0.75 & 0.73 & 0.73 & 0.73 \\
\hline 34 & 0.72 & 0.69 & 0.67 & 0.66 & 0.63 \\
\hline 35 & 0.62 & 0.60 & 0.58 & 0.57 & 0.52 \\
\hline 36 & 0.54 & 0.53 & 0.52 & 0.52 & 0.52 \\
\hline 37 & 0.70 & 0.65 & 0.63 & 0.61 & 0.56 \\
\hline 38 & 0.57 & 0.55 & 0.55 & 0.55 & 0.55 \\
\hline
\end{tabular}


Table 11: Results of AFDEA model for AP $=100 \%$ (Possibility Measure)

\begin{tabular}{|c|c|c|c|c|c|}
\hline \multirow{2}{*}{ Hospitals } & \multicolumn{5}{|c|}{$\alpha$-level } \\
\hline & $0 \%$ & $25 \%$ & $50 \%$ & $75 \%$ & $100 \%$ \\
\hline 1 & 0.70 & 0.70 & 0.70 & 0.70 & 0.70 \\
\hline 2 & 0.70 & 0.69 & 0.67 & 0.66 & 0.65 \\
\hline 3 & 0.85 & 0.83 & 0.81 & 0.78 & 0.77 \\
\hline 4 & 0.88 & 0.83 & 0.78 & 0.73 & 0.70 \\
\hline 5 & 0.71 & 0.69 & 0.68 & 0.66 & 0.64 \\
\hline 6 & 0.70 & 0.70 & 0.70 & 0.70 & 0.70 \\
\hline 7 & 1.50 & 1.41 & 1.33 & 1.24 & 1.16 \\
\hline 8 & 0.60 & 0.59 & 0.58 & 0.58 & 0.58 \\
\hline 9 & 0.66 & 0.64 & 0.63 & 0.62 & 0.60 \\
\hline 10 & 0.94 & 0.89 & 0.84 & 0.79 & 0.75 \\
\hline 11 & 0.61 & 0.59 & 0.58 & 0.58 & 0.58 \\
\hline 12 & 1.32 & 1.25 & 1.19 & 1.13 & 1.07 \\
\hline 13 & 0.96 & 0.91 & 0.86 & 0.82 & 0.79 \\
\hline 14 & 0.63 & 0.62 & 0.61 & 0.60 & 0.59 \\
\hline 15 & 0.69 & 0.67 & 0.66 & 0.64 & 0.63 \\
\hline 16 & 0.52 & 0.51 & 0.50 & 0.49 & 0.49 \\
\hline 17 & 0.68 & 0.67 & 0.65 & 0.64 & 0.63 \\
\hline 18 & 0.75 & 0.70 & 0.66 & 0.64 & 0.62 \\
\hline 19 & 1.25 & 1.18 & 1.12 & 1.08 & 1.06 \\
\hline 20 & 0.66 & 0.65 & 0.64 & 0.63 & 0.62 \\
\hline 21 & 0.87 & 0.82 & 0.78 & 0.76 & 0.74 \\
\hline 22 & 0.68 & 0.65 & 0.63 & 0.62 & 0.61 \\
\hline 23 & 1.01 & 0.95 & 0.90 & 0.85 & 0.81 \\
\hline 24 & 0.66 & 0.64 & 0.63 & 0.62 & 0.60 \\
\hline 25 & 0.49 & 0.48 & 0.48 & 0.47 & 0.46 \\
\hline 26 & 0.69 & 0.67 & 0.66 & 0.64 & 0.63 \\
\hline 27 & 0.50 & 0.49 & 0.48 & 0.48 & 0.48 \\
\hline 28 & 1.17 & 1.11 & 1.05 & 1.00 & 0.95 \\
\hline 29 & 0.55 & 0.54 & 0.53 & 0.52 & 0.51 \\
\hline 30 & 0.68 & 0.66 & 0.65 & 0.63 & 0.62 \\
\hline 31 & 0.83 & 0.79 & 0.74 & 0.71 & 0.70 \\
\hline 32 & 0.84 & 0.79 & 0.75 & 0.71 & 0.67 \\
\hline 33 & 0.77 & 0.76 & 0.74 & 0.73 & 0.73 \\
\hline 34 & 0.72 & 0.70 & 0.68 & 0.67 & 0.66 \\
\hline 35 & 0.62 & 0.61 & 0.59 & 0.58 & 0.57 \\
\hline 36 & 0.54 & 0.53 & 0.52 & 0.52 & 0.52 \\
\hline 37 & 0.70 & 0.66 & 0.63 & 0.62 & 0.61 \\
\hline 38 & 0.57 & 0.55 & 0.55 & 0.55 & 0.55 \\
\hline
\end{tabular}


Table 12: Results of FDEA model based on $\alpha$-level based approach

\begin{tabular}{|c|c|c|c|c|c|}
\hline \multirow{2}{*}{ Hospitals } & \multicolumn{5}{|c|}{$\alpha$-level } \\
\hline & $0 \%$ & $25 \%$ & $50 \%$ & $75 \%$ & $100 \%$ \\
\hline 1 & 0.70 & 0.70 & 0.70 & 0.70 & 0.70 \\
\hline 2 & 0.70 & 0.68 & 0.66 & 0.60 & 0.60 \\
\hline 3 & 1.00 & 1.00 & 1.00 & 1.00 & 1.00 \\
\hline 4 & 0.94 & 0.91 & 0.87 & 0.81 & 0.81 \\
\hline 5 & 0.84 & 0.80 & 0.76 & 0.72 & 0.72 \\
\hline 6 & 1.00 & 1.00 & 1.00 & 1.00 & 1.00 \\
\hline 7 & 1.00 & 1.00 & 1.00 & 1.00 & 1.00 \\
\hline 8 & 0.82 & 0.82 & 0.82 & 0.82 & 0.82 \\
\hline 9 & 0.78 & 0.76 & 0.74 & 0.65 & 0.65 \\
\hline 10 & 0.94 & 0.87 & 0.80 & 0.55 & 0.55 \\
\hline 11 & 0.64 & 0.62 & 0.62 & 0.62 & 0.62 \\
\hline 12 & 1.00 & 1.00 & 1.00 & 0.96 & 0.96 \\
\hline 13 & 1.00 & 0.95 & 0.88 & 0.69 & 0.69 \\
\hline 14 & 0.62 & 0.61 & 0.59 & 0.57 & 0.57 \\
\hline 15 & 0.70 & 0.68 & 0.65 & 0.61 & 0.61 \\
\hline 16 & 0.59 & 0.57 & 0.56 & 0.56 & 0.56 \\
\hline 17 & 0.77 & 0.75 & 0.73 & 0.64 & 0.64 \\
\hline 18 & 0.75 & 0.66 & 0.62 & 0.52 & 0.52 \\
\hline 19 & 1.00 & 1.00 & 1.00 & 1.00 & 1.00 \\
\hline 20 & 0.77 & 0.75 & 0.74 & 0.74 & 0.74 \\
\hline 21 & 0.89 & 0.82 & 0.79 & 0.79 & 0.79 \\
\hline 22 & 0.78 & 0.75 & 0.73 & 0.60 & 0.60 \\
\hline 23 & 1.00 & 0.93 & 0.86 & 0.57 & 0.57 \\
\hline 24 & 0.68 & 0.66 & 0.63 & 0.56 & 0.56 \\
\hline 25 & 0.63 & 0.61 & 0.60 & 0.59 & 0.59 \\
\hline 26 & 0.76 & 0.74 & 0.72 & 0.68 & 0.68 \\
\hline 27 & 0.64 & 0.63 & 0.63 & 0.63 & 0.63 \\
\hline 28 & 1.00 & 1.00 & 1.00 & 0.72 & 0.72 \\
\hline 29 & 0.58 & 0.57 & 0.55 & 0.54 & 0.54 \\
\hline 30 & 0.80 & 0.78 & 0.78 & 0.78 & 0.78 \\
\hline 31 & 0.83 & 0.73 & 0.65 & 0.53 & 0.53 \\
\hline 32 & 0.85 & 0.78 & 0.75 & 0.62 & 0.62 \\
\hline 33 & 1.00 & 1.00 & 1.00 & 1.00 & 1.00 \\
\hline 34 & 0.71 & 0.63 & 0.59 & 0.54 & 0.54 \\
\hline 35 & 0.63 & 0.61 & 0.59 & 0.56 & 0.56 \\
\hline 36 & 0.54 & 0.53 & 0.53 & 0.53 & 0.53 \\
\hline 37 & 0.70 & 0.67 & 0.65 & 0.51 & 0.51 \\
\hline 38 & 0.60 & 0.60 & 0.60 & 0.60 & 0.60 \\
\hline
\end{tabular}

